$11-1-2021$

\title{
Necesidades y atención en salud sexual y reproductiva de mujeres migrantes en México: Un estudio desde Ciudad Juárez-Volumen 1
}

Lucía Vázquez Quesada

Population Council

Jesús Peña

Isabel Vieitez Martínez

Population Council

Follow this and additional works at: https://knowledgecommons.popcouncil.org/departments_sbsr-pgy How does access to this work benefit you? Let us know!

\section{Recommended Citation}

Vázquez Quesada, Lucia, Jesús Peña, and Isabel Vieitez Martínez. 2021. "Necesidades y atención en salud sexual y reproductiva de mujeres migrantes en México: Un estudio desde Ciudad Juárez-Volumen 1." México: Population Council y El Colegio de la Frontera Norte. 


\section{Volumen 1}

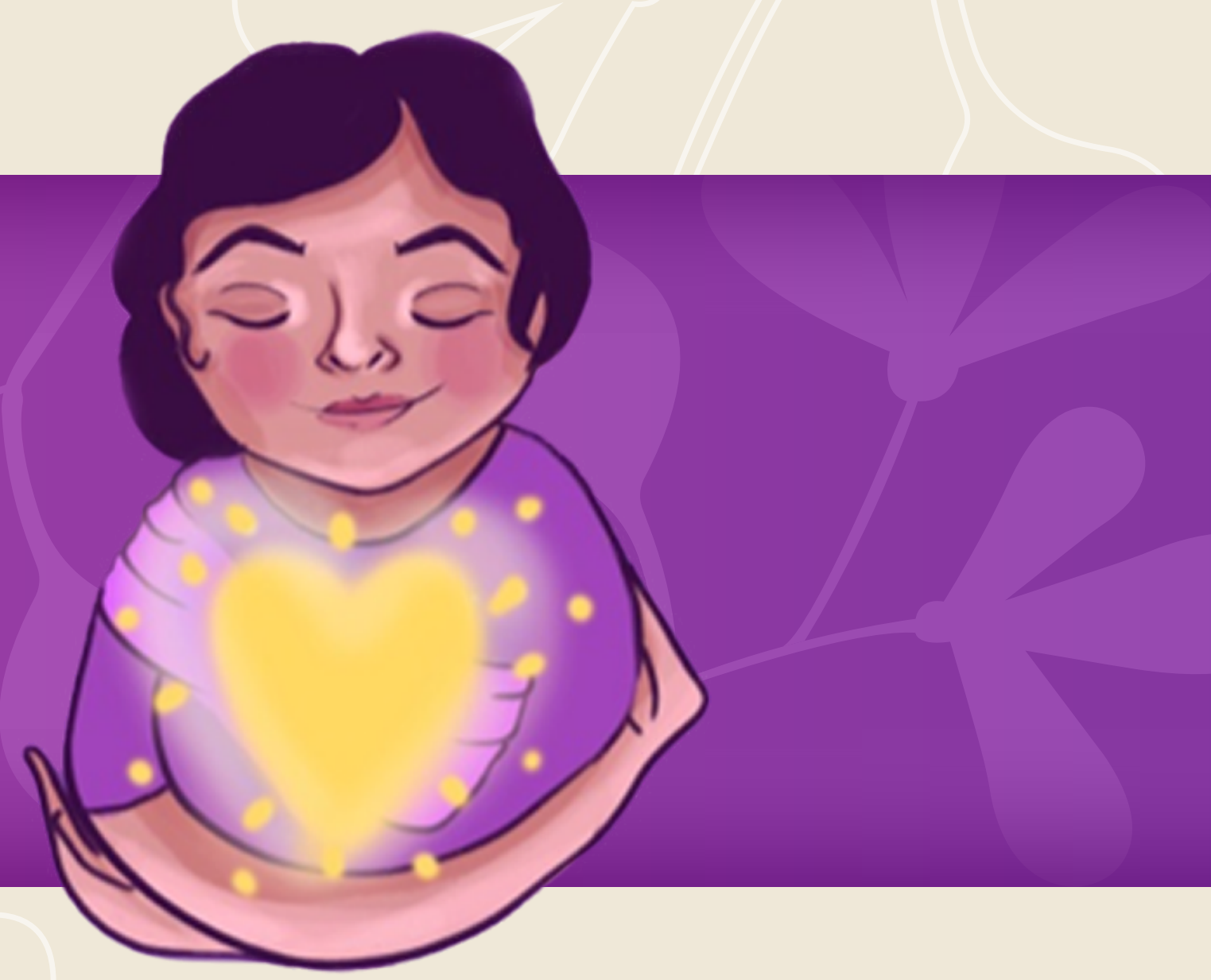

\section{NECESIDADES Y ATENCIÓN EN SALUD SEXUAL Y REPRODUCTIVA DE MUJERES MIGRANTES EN MÉXICO}

Un estudio desde Ciudad Juárez, Chihuahua 
NECESIDADES Y ATENCIÓN EN SALUD SEXUAL Y REPRODUCTIVA DE MUJERES MIGRANTES EN MÉXICO

Un estudio desde Ciudad Juárez, Chihuahua

Informe de resultados

\section{VOLUMEN 1}

NOVIEMBRE 2021 


\section{INVESTIGACIÓN REALIZADA POR}

Population Council, Inc. y El Colegio de la Frontera Norte

\section{EQUIPO DE INVESTIGACIÓN}

Investigadora Principal

\section{Lucía M. Vázquez-Quesada}

Investigadora de Population Council, México

Protocolo de investigación, coordinación del estudio, redacción del informe

\section{INVESTIGADORES}

\section{Jesús Peña}

Investigador del Departamento de Estudios Sociales, El Colegio de la Frontera Norte

Co-cordinación del estudio en Cd. Juárez, análisis de datos y redacción del informe

\section{Isabel Vieitez-Martínez}

Directora de Population Council, México

Supervisión del protocolo de investigación y revisión de informe
Recolección de datos

\section{Karla Delgado}

Coordinación del trabajo de campo, encuestadora y entrevistadora

\section{Judith Arriaga Carolina Montalvo}

Encuestadora y/o entrevistadora

\section{AGRADECIMIENTOS}

A todas las mujeres migrantes encuestadas. Albergues: Pan de Vida, Esperanza Para Todos, Leona Vicario, "Kiki" Romero, San Matías y El Buen Samaritano.

\section{AVISO LEGAL}

Se permite la reproducción total o parcial de esta publicación para fines educativos, de investigación y cualquier otro fin libre de lucro, siempre y cuando se cite la fuente.

\section{CITA SUGERIDA}

Vázquez-Quesada, Lucía M., Peña, Jesús y Vieitez, Isabel. "Necesidades y Atención en Salud Sexual y Reproductiva de Mujeres Migrantes en México. Un estudio desde Ciudad Juárez, Chihuahua." Vol. I. México: Population Council y El Colegio de la Frontera Norte. 


\section{PREFACIO}

\section{(Volumen I y II)}

En sus más de 30 años de trabajo en México, el Population Council ha impulsado investigaciones sobre Salud Sexual y Reproductiva (SSR) con diversas poblaciones, con el fin de impulsar la toma de decisiones que mejoren la vida de las personas con base en evidencia.

En 2019, cuando el equipo de investigación de esta organización internacional nogubernamental y sin fines de lucro, se dio a la tarea de realizar una investigación sobre intervenciones que atienden las necesidades de SSR de mujeres extranjeras que migran y están en tránsito por México (mujeres migrantes), se dio cuenta de que había poca información (actualizada) sobre las necesidades que tiene esta población en el continuum de atención posible. Por ello, la investigación buscó responder las siguientes preguntas: ¿qué necesidades en SSR tienen las mujeres migrantes extranjeras en tránsito por México? ¿qué servicios en SSR brindan a estas mujeres las organizaciones de la sociedad civil (OSCs) que trabajan con y para la población migrante? y ¿qué intervenciones, a nivel global, para atender las necesidades en SSR de las mujeres migrantes tienen un impacto positivo en esta población?

Se plantearon distintos proyectos de investigación:

1. El presente estudio, que busca obtener respuestas directamente de las mujeres migrantes en tránsito por México, que se encuentran en la frontera norte del país (Ciudad Juárez, Chihuahua)

2. Un diagnóstico situacional sobre las necesidades de mujeres migrantes y acceso a servicios de SSR al inicio del viaje migratorio por México, en la frontera sur del país (Tapachula, Chiapas)

3. Un mapeo de actores de la sociedad civil que brindan servicios en SSR a mujeres migrantes en siete estados que son parte de la ruta migratoria

4. Una revisión sistemática de literatura sobre intervenciones para cubrir las necesidades de SSR de esta población (en revisión por pares). 
El presente estudio se realizó con la valiosa colaboración de El Colegio de la Frontera Norte, A.C. Aunque no es exhaustivo de las necesidades de SSR de las mujeres que migran y se encuentran en tránsito por México, retoma las voces de estas personas y brinda un panorama descriptivo poco estudiado con anterioridad; además, coincide con un momento excepcional de la historia reciente de la humanidad: la pandemia por COVID-19. Esperamos que la investigación contribuya a expandir la evidencia académica y no académica sobre el tema para la toma de decisión de autoridades gubernamentales, organismos y agencias internacionales, prestadores de servicios de salud, y organizaciones de la sociedad civil, en beneficio del bienestar de las mujeres y personas que migran y que se encuentran en territorio mexicano. 


\section{CONTENIDO}

Prefacio

$\begin{array}{ll}\text { I. Introducción } & 8\end{array}$

$\begin{array}{ll}\text { II. Metodología } & 11\end{array}$

2.1. Población de estudio 11

2.2. Sitio de estudio 11

2.3. Selección de la muestra 12

2.4. Instrumento 14

2.5. Levantamiento de datos 15

2.6. Consideraciones éticas (COVID-19 y de cuidado de las participantes

y el equipo de investigación) 16

III. Características de la población y ruta migratoria 18

3.1. Características de la población 18

3.2.1 Salida de su lugar de origen $\quad 20$

3.2.2. Trayecto por México $\quad 21$

3.2.3. Llegada a Ciudad Juárez 23

3.2.4. Destino 24

IV. Salud sexual y reproductiva 25

4.1. Salud en general y cuidados contra el COVID-19 25

4.2. Cuidados y preparación de SSR antes de iniciar su trayecto migratorio 27

4.3. Cuidados y problemas de SSR en el trayecto migratorio 29

$\begin{array}{ll}\text { V. Embarazo } & 37\end{array}$

5.1. Cuidados del embarazo durante el trayecto por México 37

5.2. Cuidados del embarazo en Ciudad Juárez 42

5.3 Planes de embarazo 43 
NECESIDADES Y ATENCIÓN EN SALUD SEXUAL Y REPRODUCTIVA DE MUJERES MIGRANTES EN MÉXICO

Volumen 1

VI. Opiniones y conocimiento sobre SSR

6.1. Conocimientos generales sobre SSR

6.2. Conocimiento sobre derechos de salud y acceso a atención

de población migrante extranjera en México

6.3 Valoración de experiencia migratoria en relación con problemas y cuidados de SSR 49

VII. Discusión

51

VIII. Conclusión

IX. Referencias 


\section{NECESIDADES Y ATENCIÓN EN SALUD SEXUAL Y REPRODUCTIVA DE MUJERES MIGRANTES EN MÉXICO}

Volumen 1

\section{INTRODUCCIÓN}

\section{A escala mundial, los flujos migratorios contemporáneos muestran una complejidad} sin precedentes. El sistema migratorio norteamericano no ha sido la excepción. Estudios recientes indican que los flujos migratorios que se generan y circulan por América del Norte no solamente han crecido en volumen, intensidad y distancia del desplazamiento, sino que también las características de las poblaciones migrantes se han modificado (Heredia Zubieta, 2016). Uno de los principales cambios se debe a la creciente presencia de mujeres, niños, niñas y adolescentes, asociado en parte a la presencia de unidades familiares completas en el proceso de movilidad (Ataiants et al., 2018; UNICEF, 2021). En México, de enero a agosto de 2021, se registra un total de 148, 903 eventos de personas extranjeras presentadas ante la autoridad migratoria, de las cuales $36.9 \%$ son mujeres adultas y menores de edad ${ }^{1}$ (UPMRIP, 2021).

El género como una determinante de la migración y de las experiencias migratorias ha sido estudiado en México y en otras geografías (Gabriela Díaz Prieto y Gretchen Kuhner, 2014). Para las mujeres², y para otras identidades sexogenéricas no normativas, la violencia de género vivida en sus países de origen es reportada tanto como una razón de migración que como un riesgo mayor al que enfrentan los hombres de vivir violencia sexual en el trayecto migratorio (Cesar Infante et al., 2020; Leyva-Flores et al., 2019) sexual, and psychological violence among migrants in transit through Mexico to the US; and 2. Estos riesgos y otras vulnerabilidades características de un viaje migratorio irregular, afecta la salud de las personas (Leyva Flores et al., 2016). Por lo tanto, el acceso a servicios de atención de la salud durante el desplazamiento migratorio es una necesidad fundamental para el bienestar de las poblaciones en situación de movilidad.

La salud de las poblaciones migrantes ha sido un tema central de los estudios sobre migración en décadas recientes. No obstante, los constantes y a veces dramáticos cambios sociodemográficos, de rutas y condiciones de movilidad que experimentan las poblaciones en situación de movilidad, exigen de nuevos esfuerzos de investigación que introduzcan nuevas temáticas y metodologías. Con esto en mente, el proyecto de investigación Necesidades y

\footnotetext{
1 De los 148,903 eventos, $18.2 \%$ corresponden a mujeres adultas, $7.6 \%$ a mujeres menores de edad, $11.1 \%$ a hombres menores de edad. El $63.1 \%$ restante, corresponde a hombres adultos.

2 El presente estudio define "mujer" como la construcción social de género que, en un contexto sociocultural determinado, asocia o atribuye comportamientos, actividades, expectativas específicas para quienes nacen con un aparato reproductor femenino. Este constructo generalmente se traduce en oportunidades y formas de distribución de poder desigual entre mujeres y hombre (OMS, 2018)
} 
Atención en Salud Sexual y Reproductiva de Mujeres Migrantes en México. Un estudio desde Ciudad Juárez, Chihuahua tiene como objetivo identificar las necesidades y el acceso a servicios de salud sexual y reproductiva (SSR) de mujeres en situación migratoria irregular que se encuentran en la frontera norte de México.

Para ello, se diseñó una propuesta de métodos mixtos y se priorizó recoger las experiencias y puntos de vista de las mujeres migrantes. El componente cuantitativo incluyó la recolección de datos por medio de un cuestionario estructurado a mujeres migrantes que se encontraban en albergues de Ciudad Juárez. El enfoque de este estudio fue las necesidades y el acceso a servicios de SSR durante el trayecto por México comenzando desde los preparativos para el viaje en el lugar de origen. El componente cualitativo incluyó entrevistas semi-estructuradas a esta misma población y fue posterior al inicio de la aplicación del cuestionario. En esta ocasión, el enfoque estuvo en las necesidades y cuidados durante la estancia en Ciudad Juárez, deteniéndonos en las opiniones y búsqueda de orientación en caso de requerir la interrupción de un embarazo ${ }^{3}$. La recolección de datos de los componentes comentados se llevó a cabo de junio a septiembre de 2021.

\footnotetext{
${ }^{3}$ El conocimiento sobre interrupción del embarazo resultó bajo en esta encuesta, y en el Mapeo de Actores de Organizaciones de la Sociedad Civil también se observó que es un tema que estas organizaciones atienden (hacen consejería o referencias) en menor medida que otras necesidades de SSR (Larrea-Schiavon et al., 2021)
} 
Las siguientes seis secciones del presente informe presentan un análisis descriptivo de los resultados del componente cuantitativo. En la primera sección se presenta la metodología empleada en el estudio, la cual tuvo que ser adaptada para poder hacer trabajo de campo durante la pandemia del COVID-19. En las siguientes secciones se presentan resultados descriptivos, en primer lugar, de las características sociodemográficas de la población estudiada. Posteriormente se describe la experiencia y trayectoria migratoria, incluidas las razones de salida de su lugar de origen, así como la situación de su proceso de refugio en México o asilo en Estados Unidos. En la cuarta sección se toca el tema de necesidades de atención en SSR antes de salir del lugar de origen, durante el trayecto por México y estando en Ciudad Juárez. Se incluye resultados sobre contagio y vacunación de COVID-19 estando en Ciudad Juárez. La quinta sección está dedicada al embarazo que se ha decidido continuar. Se presentan datos sobre el cuidado del embarazo en el trayecto por México y en Ciudad Juárez, así como perfiles de las mujeres embarazadas y el acceso a cuidados prenatales. Para concluir la presentación de resultados, se dedica una sección a conocimientos sobre SSR, opiniones de las mujeres encuestadas sobre el derecho a la salud, y la facilidad que tienen ellas de cuidar este aspecto de su salud en México. Finalmente, se presenta la valoración de su experiencia migratoria en relación con la manera en que ha podido cuidar de su SSR como migrante en tránsito por México. Se finaliza el reporte con una breve discusión y conclusión señalando los principales problemas de acceso a atención en SSR para las mujeres migrantes que transitan por México. 


\section{METODOLOGÍA}

\subsection{Población de estudio}

Para identificar las necesidades de SSR de las mujeres migrantes extranjeras se recurrió a una encuesta con preguntas cerradas dirigida a mujeres adultas (18+) que no tuvieran nacionalidad mexicana y preferentemente en edad reproductiva (18-49 años)4. Esta población incluye a mujeres que llegaron a Ciudad Juárez procedente del sur de México y a las que llegaron procedentes de Estados Unidos después de ser retornadas a México por autoridades migratorias estadounidenses para seguir su proceso de asilo en México, como parte de los Protocolos de Protección a Migrantes 5 . Se buscó encuestar a mujeres cis-género y transgénero, aunque la muestra final no contiene información sobre esta última subpoblación' ${ }^{6}$. El instrumento se diseñó y se aplicó solamente en el idioma español. No se suscitaron casos en los que no se pudiera aplicar el cuestionario por cuestiones de idioma.

\subsection{Sitio de estudio}

La población de interés fue buscada en albergues públicos y de la sociedad civil organizada en Ciudad Juárez, Chihuahua. Ciudad Juárez comparte frontera con los estados de Texas y Nuevo México en Estados Unidos, y fue el lugar elegido para este estudio debido a su importancia histórica como lugar de paso y recepción de población migrante extranjera, así como por su experiencia reciente con la llegada de población solicitante de asilo a Estados Unidos. Se levantaron datos en seis albergues, uno de ellos operado por el gobierno federal y el resto son iniciativas de la sociedad civil organizada.

\footnotetext{
${ }^{4}$ Se tomó en cuenta que, si bien las mujeres que han pasado la edad reproductiva tienen menor probabilidad de necesitar atención en temas de SSR explorados en el estudio, su experiencia migratoria, opiniones y observaciones abonan a los resultados finales.

5 “MPP significa 'Protocolos de Protección a Migrantes.' MPP, mejor conocido como 'Permanecer en México', fue un programa iniciado en enero de 2019 mediante el cual los solicitantes de asilo se vieron obligados a esperar en México mientras buscaban asilo en los Estados Unidos" (National Immigrant Justice Center, 2021).

${ }^{6}$ No obstante, en los albergues donde se levantaron los datos no se encontraron personas transgénero. Se intentó levantar datos en un albergue que contaba con población transgénero, pero un brote de COVID-19 en ese espacio durante el periodo de trabajo de campo, impidió proseguir con la recolección de datos.
} 


\subsection{Selección de la muestra}

Debido a la concentración de esta población en albergues, se recurrió a estos espacios para tener acceso a la población de interés. La selección de la muestra consistió en dos etapas. La primera fue la selección de albergues como unidad primaria de muestreo y la selección de mujeres migrantes como unidades secundarias. Se seleccionaron los principales espacios en cuestión de recepción de población extranjera femenina, así como los que accedieron a colaborar con el proyecto tomando en cuenta las restricciones impuestas por la pandemia de COVID-19.

De acuerdo con las expectativas iniciales del proyecto, el tamaño de la muestra fue establecida en 300 cuestionarios. El pausado y escaso flujo de personas migrantes extranjeras en Ciudad Juárez durante el periodo de trabajo de campo hizo posible invitar a participar en la encuesta a casi toda la población de interés que llegó a los espacios seleccionados. No obstante, la falta de población de interés del estudio hizo que alcanzar los 300 cuestionarios no fuera posible dentro del tiempo establecido para la recolección de datos. Finalmente, se lograron recolectar 266 cuestionarios. La recolección de datos se llevó a cabo del 3 de junio al 30 de septiembre de 2021.

Figura 1. Cartel colocado en albergues invitando a participar en el estudio

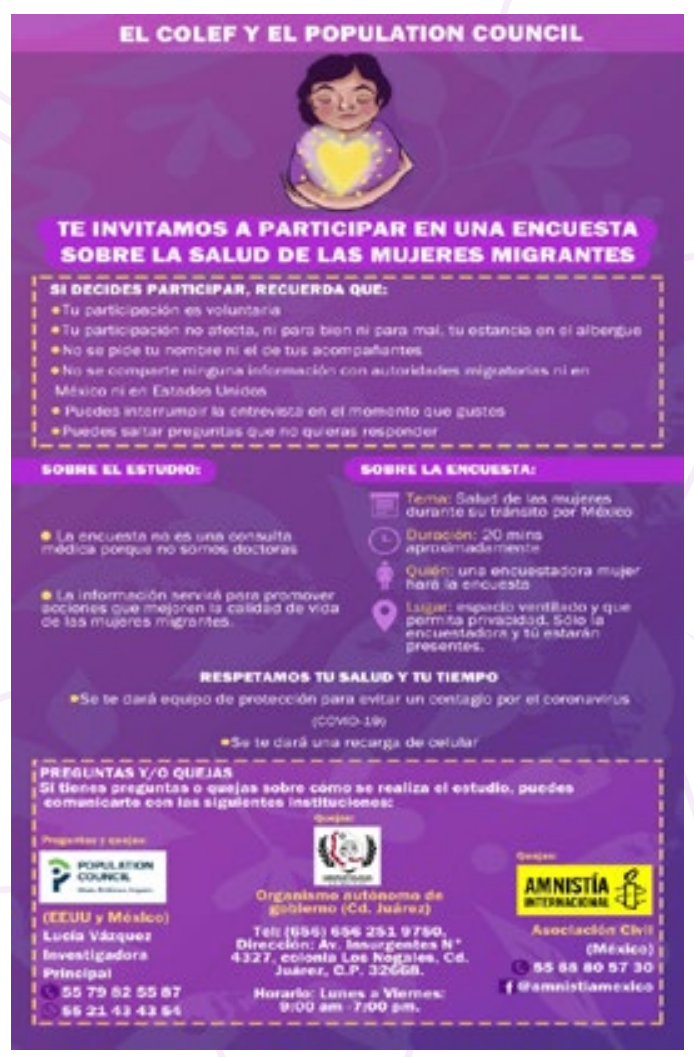

En los espacios seleccionados se colocó un cartel invitando a las mujeres a participar. El cartel contenía datos de contacto para atender dudas o quejas sobre el proyecto o el desempeño del personal de campo. Adicionalmente, personal encargado del albergue invitó a las mujeres a participar informando que era de manera voluntaria y que su decisión de participar o no, no afectaría su estancia en el albergue. 
Otro material que fue desplegado en los albergues fue un directorio de proveedores de servicios y apoyo en temas de salud sexual y reproductiva, incluyendo violencia de género y suspensión del embarazo. Al final de cada cuestionario, se refirió el directorio a las informantes.

En el 2019, se suscitó una transición residencial de una parte de la población migrante extranjera que dejó los albergues para residir en hoteles en la zona centro de la ciudad o en casas de renta en distintas zonas. Con esto en mente, y de nuevo con el objetivo de alcanzar a la mayor cantidad de nuestra población objetivo, se decidió aplicar cuestionarios en los alrededores del Centro de Atención Integral a Migrantes del Estado de Chihuahua localizada en el centro de la ciudad. Se seleccionaron mujeres extranjeras con menos de un año de estancia en la ciudad y que no vivían en albergues (ver cuadro 1). Debido a la temática del cuestionario, se decidió que todas las entrevistas fueron realizadas por entrevistadoras (mujeres cis-género) capacitadas y con experiencia en la recolección de datos cuantitativa.

Foto1. Exterior del albergue Pan de Vida

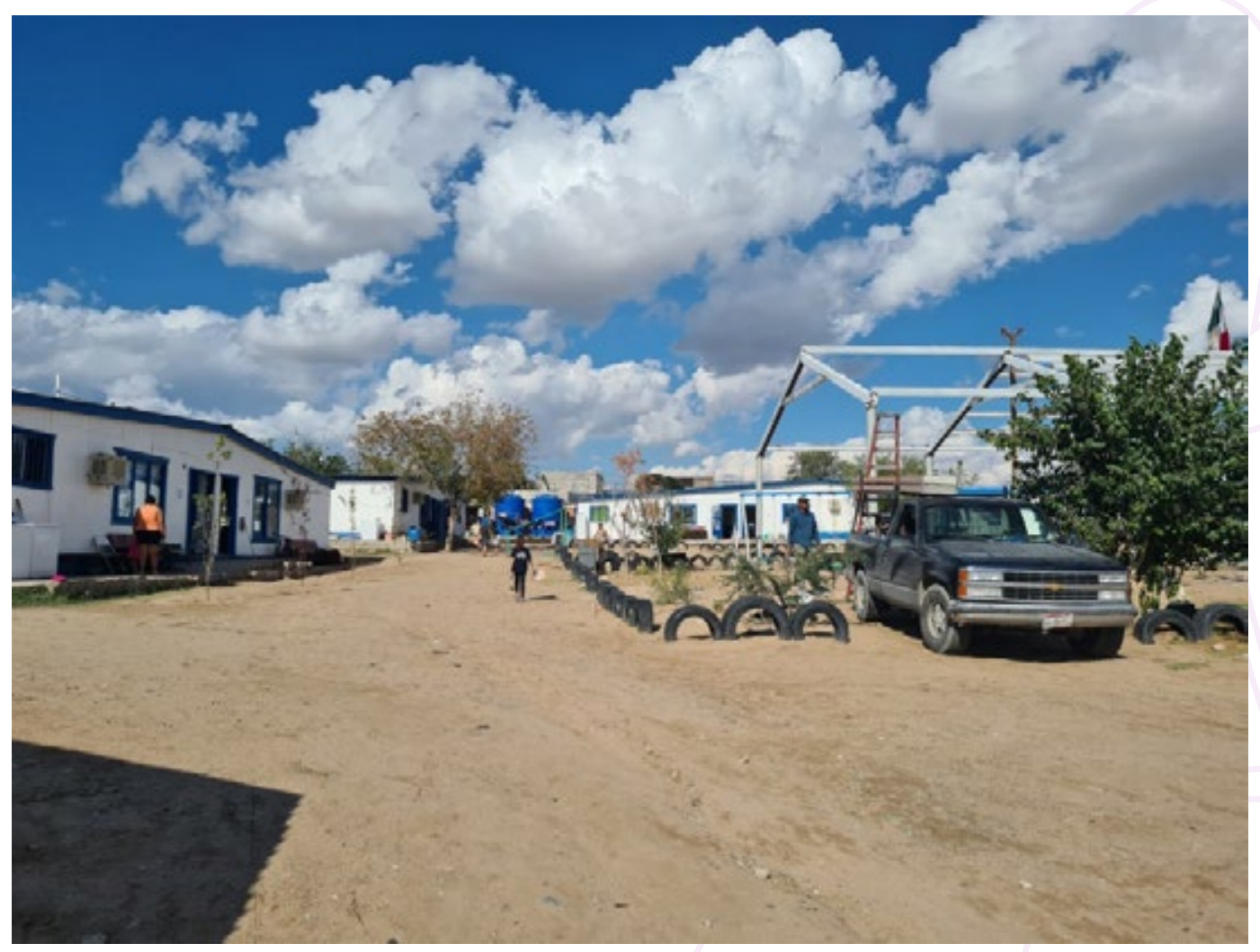


Cuadro 1. Espacios de recolección de datos

\section{Espacio}

Albergue Pan de Vida

Centro Integrador para Migrantes Leona Vicario

Esperanza para Todos

San Matías

Albergue Buen Samaritano

Gimnasio “Kiki Romero”

Vía pública Zona centro / CAIM

\subsection{Instrumento}

Para el diseño del cuestionario se utilizaron cuatro ejes temáticos:

1. Características sociodemográficas básicas y trayecto migratorio ${ }^{7}$

2. Necesidades de SSR en el lugar de origen, durante el trayecto por México y durante su estancia en Ciudad Juárez

3. Cuidados del embarazo y planificación familiar (anticoncepción)

4. Opinión y conocimiento sobre SSR. El cuestionario no incluyó preguntas sobre si las encuestadas habían vivido o no una violación (se limitó a preguntar por "tocamientos inapropiados"). Esto se debió a la consideración de que tratar el tema de una violación requiere de un objetivo específico, así como de un plan de respuesta (necesario) y de incidencia (preferentemente) para su atención y prevención (Ellsberg \& Heise, 2013), lo cual no estaba dentro de la especificidad y posibilidades del proyecto.

\footnotetext{
7 Para la elaboración del cuestionario, se utilizaron, con la anuencia del equipo de investigación responsable, preguntas generadas para el proyecto de investigación "Migración y Salud en Tijuana", que se lleva a cabo por el Colegio de la Frontera Norte (Dra. letza Bohorquez), la Universidad Nacional Autónoma de México (Dr. Juan Pablo Gutiérrez), la Universidad de San Diego (Rafael Fernández de Castro), y Population Council (Isabel Vieitez). Además, se utilizaron opciones de respuesta de la publicación Migrants in transit through Mexico to the US: Experiences with violence and related factors, 2009-2015 (Leyva-Flores et al., 2019) sexual, and psychological violence among migrants in transit through Mexico to the US; y de un instrumento de recolección de datos diseñado por Médicos del Mundo para el estudio Mujeres migrantes en Tapachula: barreras y facilitadores para el acceso a la salud sexual y reproductiva en 2020 (Vázquez-Quesada et al., 2021)
} 
En conjunto, se trata de un cuestionario que permite describir las principales necesidades de SSR de las mujeres migrantes extranjeras durante el trayecto migratorio en México, y medir la manera en que cuidan su SSR con base en sus conocimientos, creencias, recursos y el contexto de movilidad, y de estancia en albergues. La calibración del instrumento se realizó por medio de una fase de pilotaje en la que se levantaron diez cuestionarios.

\subsection{Levantamiento de datos}

Para el levantamiento de los datos, se reconfiguraron algunos de los procesos y equipo para encuestas digitales que por más de 15 años han sido utilizadas por la Encuesta de Migración en la Frontera Norte realizada por el Colegio de la Frontera Norte, CONAPO, SRE, UPM, entre otras instituciones públicas con el objetivo de agilizar el levantamiento y procesamiento de los datos.

Los cuestionarios fueron levantados de manera digital utilizando tabletas con un software en sistema Android desarrollado para este proyecto. Se hicieron dos versiones que fueron sometidas a prueba hasta lograr una encuesta visualmente clara, con secuencia lógica, con opciones de respuesta adecuados, incluidas las opciones de "no sabe" y "no responde" para todas las preguntas, así como una opción para aceptar otras respuestas escritas, y que fuera amigable a las usuarias. Además, se incluyó el botón "Pase a la siguiente persona (participante)" visible en cada pantalla, para los casos en que la encuesta deba interrumpirse por ausencia de la entrevistada o porque ésta ya no desea continuar.

Debido a las restricciones de acceso en algunos albergues por las medidas de prevención contra el COVID-19, y de acuerdo con el protocolo de prevención de contagios desarrollado para este estudio, la recolección de datos implementó una modalidad híbrida. En los albergues sin contagios y con condiciones que permitieran aminorar el riesgo, como contar con espacios abiertos y ventilados, los datos fueron recabados por personal del proyecto. En los lugares que no cumplían con estos requisitos o que no permitían el acceso a personal externo, los datos fueron recabados por personal del albergue. Así, el estudio requirió de un trabajo colaborativo con el personal a cargo de los albergues. Profesionales en psicología o trabajo social (mujeres) de estas organizaciones, fueron capacitadas en el uso de la tableta y en el contenido y aplicación del cuestionario, recibiendo un apoyo económico por cada cuestionario. Para cuidar la confiabilidad de los datos, con permiso de las encuestadas, el audio de todos los cuestionarios fue grabado para posterior revisión por el equipo de investigación. 


\subsection{Consideraciones éticas (COVID-19 y de cuidado de las participantes y el equipo de investigación)}

El estudio contó con la aprobación del Comité de Ética (IRB) del Population Council (protocolo \#920). El trabajo de campo se realizó en un contexto de pandemia, por lo que se priorizó ante todo la seguridad de entrevistadoras y entrevistadas. La recolección de datos se realizó siguiendo las indicaciones de seguridad sanitarias de la OMS y de la Secretaría de Salud de México, y se incorporó al protocolo de investigación un protocolo para la prevención y actuación antes un evento de contagio. Todo el equipo del proyecto recibió capacitación en medidas de ciudad para evitar contagios. Adicionalmente, se recibieron capacitaciones en medidas de autocuidado de salud mental y sobre temas de género y diversidad sexual.

Al inicio de la encuesta, cada participante recibió un "kit COVID" que consta de una mascarilla, gel o spray desinfectante y toallas desinfectantes (ver fotografías $\mathbf{2}$ y $\mathbf{3}$ ). Al final de la entrevista, se comentó con las informantes que el equipo de investigación dejaba un directorio de SSR en el albergue. Además, como compensación por su tiempo, recibieron una tarjeta de recarga para teléfono móvil de Telcel por cien pesos (ver fotografías $\mathbf{2}$ y 3), y se sugirió que, de necesitar algún servicio, podían utilizar dicha compensación para hacer las llamadas requeridas y buscar apoyo. 
NECESIDADES Y ATENCIÓN EN SALUD SEXUAL Y REPRODUCTIVA DE MUJERES MIGRANTES EN MÉXICO

Volumen 1

Fotografías 2 y 3: Entrega de kit contra COVID-19 y tarjeta de recarga telcel para teléfono móvil

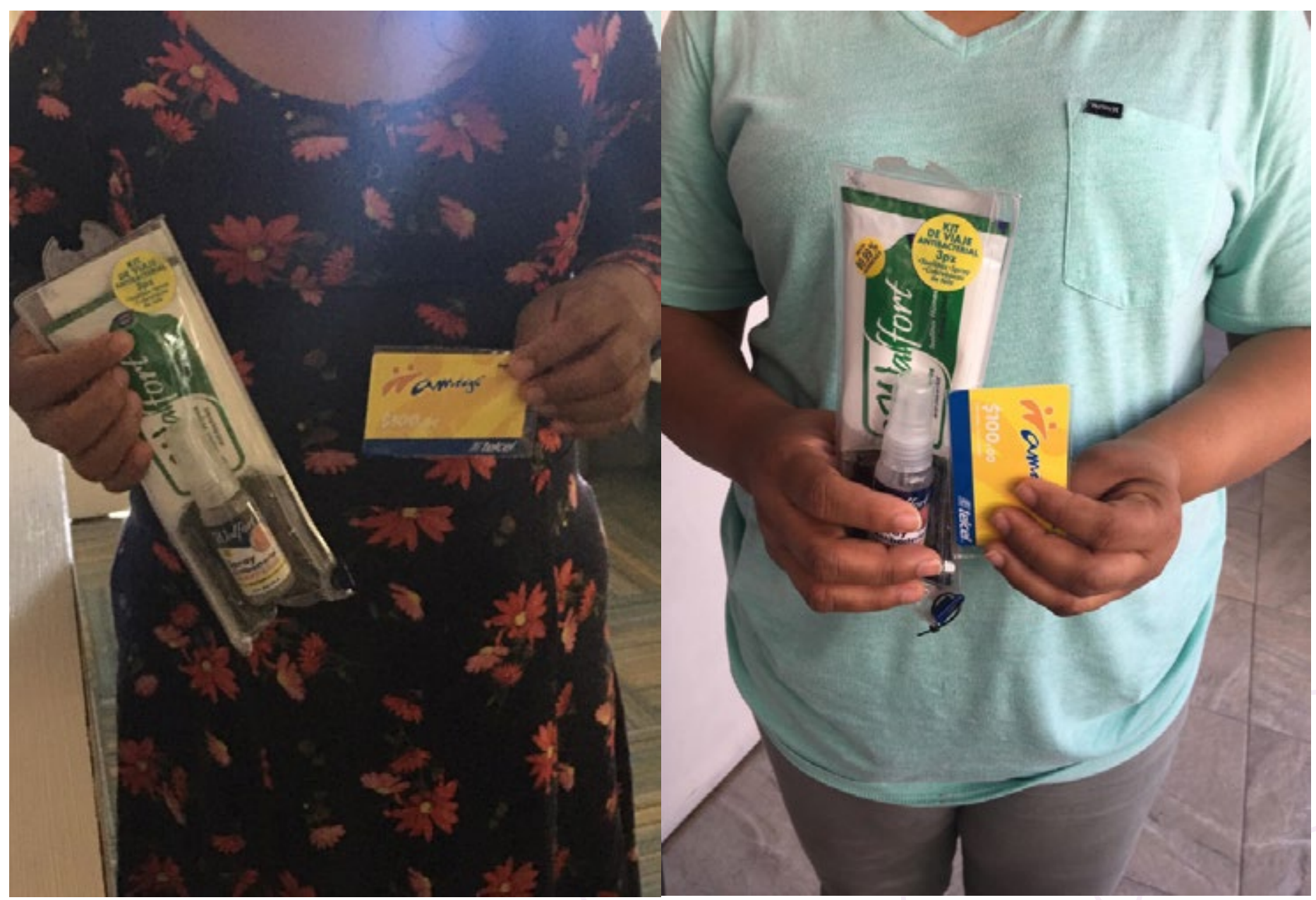

Fuente: Karla Delgado

El protocolo de investigación también consideró la salud mental de las mujeres encuestadas y de las encuestadoras, por lo que se puso a disposición de ambas un servicio de psicología a distancia y se capacitó al equipo de investigación en Primeros Auxilios Psicológicos. La grabación de la capacitación permaneció a disposición de las encuestadoras también durante el tiempo de recolección de datos para su continua referencia. No se reportó ningún episodio adverso derivado de esta investigación. 


\section{CARACTERÍSTICAS DE LA POBLACIÓN Y RUTA MIGRATORIA}

\subsection{Características de la población}

La población de mujeres extranjeras en Ciudad Juárez durante la etapa de recolección de datos estaba compuesta casi en su totalidad por persona nacidas en Guatemala, el Salvador y Honduras, siendo este último el principal país de nacimiento de la población encuestada ${ }^{8}$. Solamente se encontró a dos mujeres que no había nacido en algún país de Centroamérica, siendo este Cuba. Con respecto a la edad, se encontró una media de 29.9 años de edad, una moda de 24 años y una mediana de 28 años, con una desviación estándar de 7.5. La persona de mayor edad encuestada contaba con 60 años. Por grupos de edad, un $61 \%$ de las encuestadas se encuentra entre los 26 y 45 años.

Para identificar la identidad étnica, las respuestas preestablecidas permitían elegir más de una identidad y se incluyó la opción otra. La mayoría de las mujeres encuestadas se identifica como mestiza (61.8\%). Sobre el estado civil, destaca que un $47.7 \%$ es soltera (ver cuadro 2 ). Un 92.5\% de las informantes son madres. El número promedio de hijos o hijas es de 2.2 .

8 Durante el 2021, arribaron a México alrededor de 16 mil personas de nacionalidad haitiana. No obstante, durante el periodo de levantamiento de datos de esta investigación, esta población no había llegado a los albergues donde se levantaron las encuestas. Al cierre de este proyecto, la población haitiana estaba concentrada principalmente en Ciudad Acuña, Coahuila y en Matamoros y Reynosa en el estado de Tamaulipas. 
NECESIDADES Y ATENCIÓN EN SALUD SEXUAL Y REPRODUCTIVA DE MUJERES MIGRANTES EN MÉXICO

Cuadro 2. Distribución porcentual de la población encuestada según características sociodemográficas seleccionadas, 2021 ( $n=266)$

\begin{tabular}{|c|c|}
\hline País de Nacimiento & Porcentaje \\
\hline Honduras & $53.4 \%$ \\
\hline Guatemala & $31.6 \%$ \\
\hline El Salvador & $10.9 \%$ \\
\hline Nicaragua & $3.4 \%$ \\
\hline Cuba & $0.8 \%$ \\
\hline Identidad étnica & Porcentaje \\
\hline Mestiza & $61.8 \%$ \\
\hline Indígena & $16.7 \%$ \\
\hline Afrodescendiente & $1.5 \%$ \\
\hline Garífuna & $0.8 \%$ \\
\hline Otra & $2.3 \%$ \\
\hline Grupos de edad & Porcentaje \\
\hline 18 a 25 años & $35 \%$ \\
\hline 26 a 45 años & $61 \%$ \\
\hline 46 y más & $4 \%$ \\
\hline Estado Civil & Porcentaje \\
\hline Unión libre & $25.6 \%$ \\
\hline Casada & $22.2 \%$ \\
\hline Divorciada o separada & $1.9 \%$ \\
\hline Soltera & $47.7 \%$ \\
\hline Viuda & $2.6 \%$ \\
\hline Escolaridad & Porcentaje \\
\hline Educación básica (primaria o secundaria) & $65.3 \%$ \\
\hline Preparatoria o carrera técnica & $28.7 \%$ \\
\hline Licenciatura & $6 \%$ \\
\hline
\end{tabular}

Fuente: Elaboración propia. 


\subsubsection{Salida de su lugar de origen}

Con respecto a la principal razón por la que dejaron su lugar de origen, la razón con más menciones fue para huir de la violencia asociada a pandillas y crimen organizado (49.2\%). Observando estos datos por país de nacimiento se identifican importantes diferencias entre países. Las mujeres salvadoreñas son las que en mayor proporción dejaron su país para huir de la violencia asociada al crimen organizado y pandillas (62.1\%). Esta razón para la migración reporta porcentajes similares para las nacidas en Honduras y Guatemala. Por su parte, las mujeres de nacionalidad nicaragüense decidieron emigrar debido a persecución política (ver cuadro 3).

Cuadro 3. Distribución porcentual de la población encuestada por razones de salida del lugar de residencia habitual, según país de nacimiento, 2021 ( $n=266)$

\begin{tabular}{lllllll} 
Razón & Total & Honduras & Guatemala & El Salvador & Nicaragua & Otro \\
$\begin{array}{l}\text { Buscar mejores } \\
\text { oportunidades } \\
\text { laborales }\end{array}$ & $27.4 \%$ & $31 \%$ & $25 \%$ & $13.8 \%$ & $22.2 \%$ & $100 \%$ \\
\hline $\begin{array}{l}\text { Huir de la violencia } \\
\text { (pandillas, crimen } \\
\text { organizado) }\end{array}$ & $49.2 \%$ & $50 \%$ & $47.6 \%$ & $62.1 \%$ & $22.2 \%$ & $0 \%$ \\
\hline $\begin{array}{l}\text { Violencia de género/ } \\
\text { intrafamiliar }\end{array}$ & $15.8 \%$ & $12 \%$ & $22.6 \%$ & $17.2 \%$ & $11.1 \%$ & $0 \%$ \\
\hline $\begin{array}{l}\text { Persecución política } \\
\text { Pobreza }\end{array}$ & $3.8 \%$ & $2.1 \%$ & $2.4 \%$ & $3.4 \%$ & $44.5 \%$ & $0 \%$ \\
\hline
\end{tabular}

Nota: Pregunta permite respuesta de opción múltiple Fuente: Elaboración propia 


\subsubsection{Trayecto por México}

La documentación con la que contaban para ingresar a México constaba de alguna credencial de identificación como es el Documento Único de Identidad (DUI) expedida en el Salvador, o el Documento Nacional de Identidad de Honduras. Solamente un $4 \%$ salió de su país de origen sin ningún tipo de documento (ver cuadro 4).

Cuadro 4. Distribución porcentual de documentos de identidad y migratorios con los que contaba al ingresar a México $(n=266)$

\begin{tabular}{ll} 
Documento & Porcentaje \\
\hline Certificado de nacimiento & $12.5 \%$ \\
\hline Credencial de identificación/ DUI & $71.3 \%$ \\
\hline Pasaporte & $9.1 \%$ \\
\hline Tarjeta de visitante regional o trabajadora fronteriza & $0.8 \%$ \\
\hline Visa de turista & $0.4 \%$ \\
\hline Otro & $1.9 \%$ \\
\hline Ninguno & $4 \%$ \\
\hline
\end{tabular}

Nota: Pregunta permite respuesta de opción múltiple.

Fuente: Elaboración propia

Se les preguntó a las informantes sobre problemas y situaciones difíciles que hayan experimentado en su trayecto por México. El problema más común fue no tener dinero (92.4\%). No tener suficiente o nada de comer fue otro problema recurrente. Sobre otro tipo de situaciones, casi la mitad de las encuestadas tuvo que dormir a la intemperie y un $61 \%$ reportó haber recibido humillaciones o expresiones de rechazo. $19.8 \%$ sí reporta haber vivido tocamientos inapropiados (ver cuadro 5). 
Cuadro 5. Distribución porcentual de situaciones experimentadas durante el trayecto por México hacia la frontera norte de México, 2021 ( $n=266)$

\begin{tabular}{ll} 
Situación & Porcentaje \\
\hline No tener dinero & $92.4 \%$ \\
\hline Dejar de hacer una comida por no tener suficiente & $83.7 \%$ \\
\hline No tener nada de comer & $65.2 \%$ \\
\hline No tener nada de beber & $61.4 \%$ \\
\hline Dormir a la intemperie & $49.2 \%$ \\
\hline Recibir humillaciones o expresiones de rechazo & $61 \%$ \\
\hline Recibir amenazas o intimidación & $42.4 \%$ \\
\hline Sufrir violencia física, golpes para hacerle daño & $20.1 \%$ \\
\hline Ser tocada de manera inapropiada & $19.8 \%$ \\
\hline Le robaron alguna de sus pertenencias & $36.7 \%$ \\
\hline Secuestrada & $20.8 \%$ \\
\hline Obligada a consumir drogas o alcohol & $3.4 \%$ \\
\hline
\end{tabular}

Nota: Pregunta permite respuesta de opción múltiple. Fuente: Elaboración propia.

Sobre su proceso migratorio, se encontró que un 14\% había solicitado refugio en México ( $n=37$ mujeres). Sobre la situación de su solicitud de refugio, un 22.2\% reportó que el proceso estaba activo, a un $38.8 \%$ le habían aprobado su solicitud; mientras que a un $22.2 \%$ le rechazaron su solicitud. Un $16.6 \%$ dejó de darle seguimiento o lo abandonó completamente por lo que no sabía la situación de la solicitud.

El tiempo que les tomó en llegar a Ciudad Juárez desde que salieron de su lugar de origen fue de 15 o menos días (40.2\%), 32.2\% de más de 15 días hasta un mes y de más de un mes hasta dos meses del $12.9 \%$. Para un $14.8 \%$, el trayecto duró más de dos meses. Estos lapsos de tiempo pueden incluir tiempo de viaje y estancias temporales dentro de México, así como tiempo detenidas en un centro de detención migratoria en Estados Unidos. 


\subsubsection{Llegada a Ciudad Juárez}

El tiempo de estancia en Ciudad Juárez al momento de ser encuestadas se concentraban en un mes o menos (70.1\%). La población que se encontraba en los albergues en Ciudad Juárez durante el periodo de recolección de datos de esta investigación había sido llevada, en su mayoría, a esa ciudad por autoridades migratorias estadounidenses como parte de los Protocolos de Protección a Migrantes (PPM) después de ser detenida en su intento de cruce a Estados Unidos (62.5\%). Otras llegaron por su cuenta desde el sur de México para intentar pedir asilo a Estados Unidos por la ciudad de El Paso, Texas (26.5\%). Quedar claro que una estancia permanente en Ciudad Juárez no estaba en los planes de estas migrantes siendo solamente un $1.1 \%$ que vino a esa ciudad con la intención de vivir y trabajar (ver cuadro 6).

Cuadro 6. Distribución porcentual de la población encuestada por razones de llegada a Ciudad Juárez, 2021. (n=266)

\begin{tabular}{ll} 
Razón & Porcentaje \\
\hline Fue deportada de EE.UU. a Ciudad Juárez después de vivir en ese país & $0.4 \%$ \\
\hline $\begin{array}{l}\text { Fue retornada de EE.UU. a Ciudad Juárez después de ser detenida al } \\
\text { momento de cruzar como parte de MPP }\end{array}$ & $62.5 \%$ \\
\hline Vino a pedir asilo a EE.UU. & $26.5 \%$ \\
\hline Vino a cruzar a EE.UU. como sea posible & $1.9 \%$ \\
\hline Aquí la trajeron los guías de migrantes & $5.7 \%$ \\
\hline Vino a quedarse a vivir y trabajar & $1.1 \%$ \\
\hline Otra razón & $1.9 \%$ \\
\hline
\end{tabular}

Fuente: Elaboración propia

La documentación de las personas encuestadas no cambió mucho con relación a los documentos con los que ingresaron a México. En esta ocasión un mayor porcentaje mencionó tener su certificado de nacimiento. Con respecto a documentos otorgados por el gobierno de México, $11.7 \%$ tenía tarjeta de visitante por razones humanitarias ya sea vigente o vencida. Menos del $2 \%$ contaban con la Clave Única de Registro Poblacional (CURP) (ver cuadro 7). 
Cuadro 7. Distribución porcentual de la población encuestada por documentos de identidad y migratorios con los que contaba en Ciudad Juárez, 2021

\begin{tabular}{ll} 
Documento & Porcentaje que sí tiene el documento \\
\hline Certificado de nacimiento & $41.9 \%$ \\
\hline Credencial de identificación /DUI & $78.9 \%$ \\
\hline Pasaporte & $12.8 \%$ \\
\hline Tarjeta de visitante regional o trabajadora fronteriza & $3.8 \%$ \\
\hline Tarjeta de visitante por razones humanitarias vigente & $9.1 \%$ \\
\hline Tarjeta de visitante por razones humanitarias vencida & $2.6 \%$ \\
\hline CURP & $1.5 \%$ \\
\hline
\end{tabular}

Nota: Pregunta permite respuesta de opción múltiple

Fuente: Elaboración propia

\subsubsection{Destino}

Solamente a un $1.1 \%$ de las encuestadas le gustaría establecerse de manera definitiva en México. Se trata de una población con poca experiencia migratoria previa hacia Estados Unidos. Para un 78.8\% este es su primer intento de llegar a Estados Unidos. Para lograr este objetivo, un 56.8\% había solicitado asilo en Estados Unidos. En un 89.3\% de los casos, el asilo estaba en trámite. A un $4 \%$ le fue rechazada su solicitud. El $6.7 \%$ restante no sabía con seguridad la situación de proceso de asilo. 


\section{SALUD SEXUAL Y REPRODUCTIVA}

\subsection{Salud en general y cuidados contra el COVID-19}

Un 7.3\% de las encuestadas considera que su salud es muy buena. Por el contrario, un 3.1\% la considera muy mala. La mayoría se coloca en la categoría de regular (ver gráfica 1).

Gráfica 1. Distribución porcentual de autovaloración de su estado de salud en general, 2021

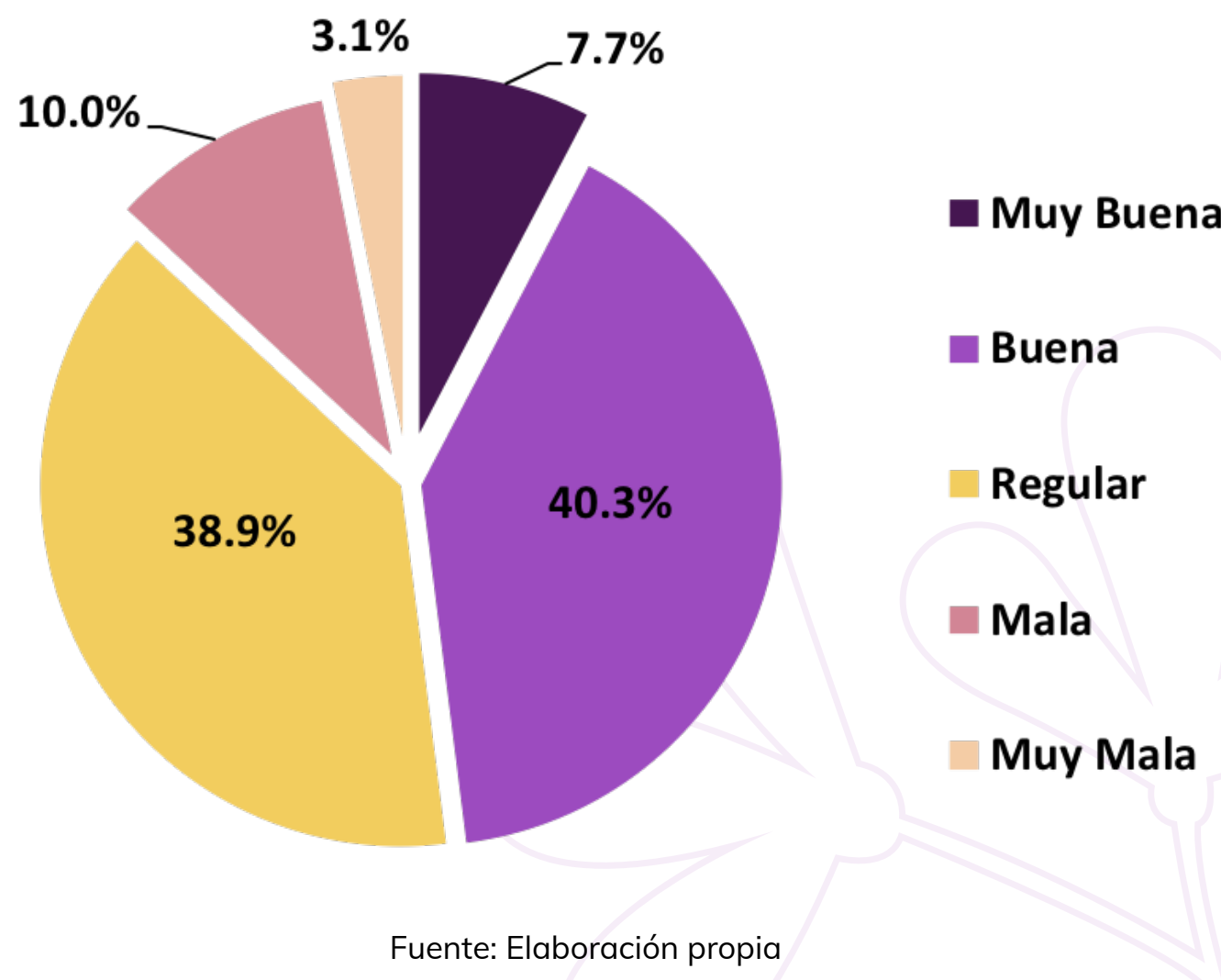

La pandemia del Covid-19 representó otro reto para las poblaciones en situación de movilidad durante el 2020 y 2021. Los datos de este reporte fueron recabados en los inicios de los programas de vacunación masiva en el norte de México, por lo que se decidió agregar preguntas a la encuesta sobre prevención, casos de contagio, atención en caso de contagio y vacunación. Con respecto a contagios, un $14.2 \%$ reportó haber tenido Covid-19 o que alguien con quien ella vive lo tuvo. De las personas que tuvieron síntomas, un $78.4 \%$ se hicieron la prueba para detectar la enfermedad. Un $31 \%$ de las pruebas resultaron positivas. 
Foto 4. Habitaciones el Hotel Filtro, espacio especializado en el cuidado y prevención de contagios de COVID-19

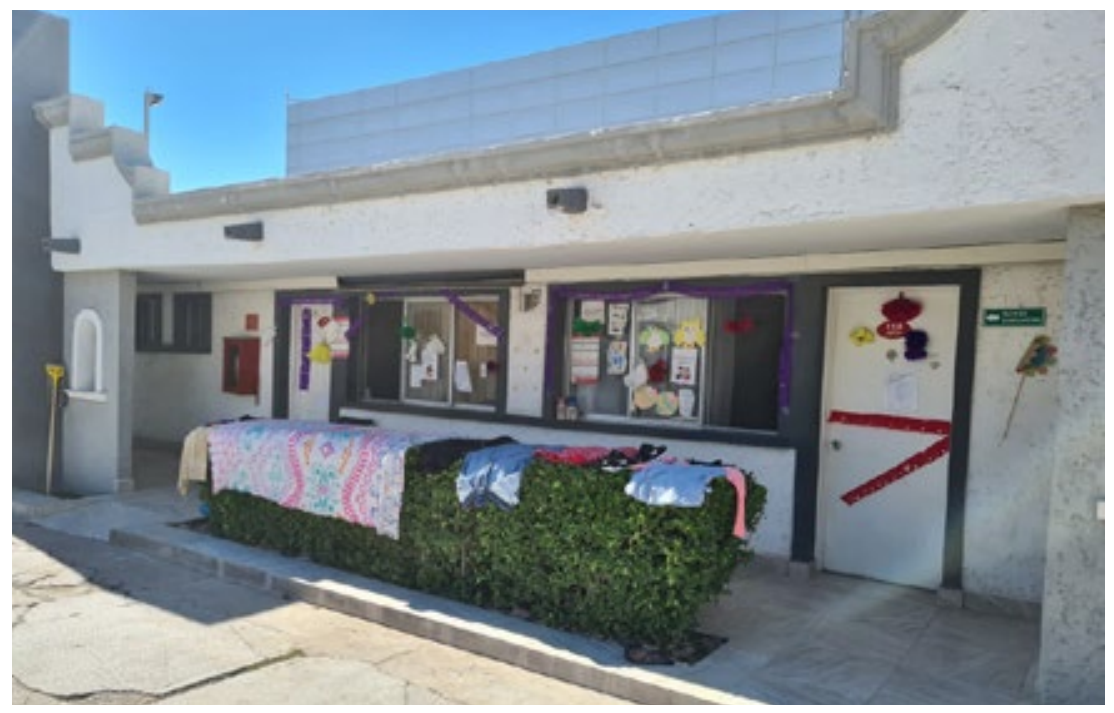

Fuente: Jesús Peña

Foto 5. Poster con información para la prevención de contagios de COVID-19 dentro del albergue Esperanza para Todos en Ciudad Juárez

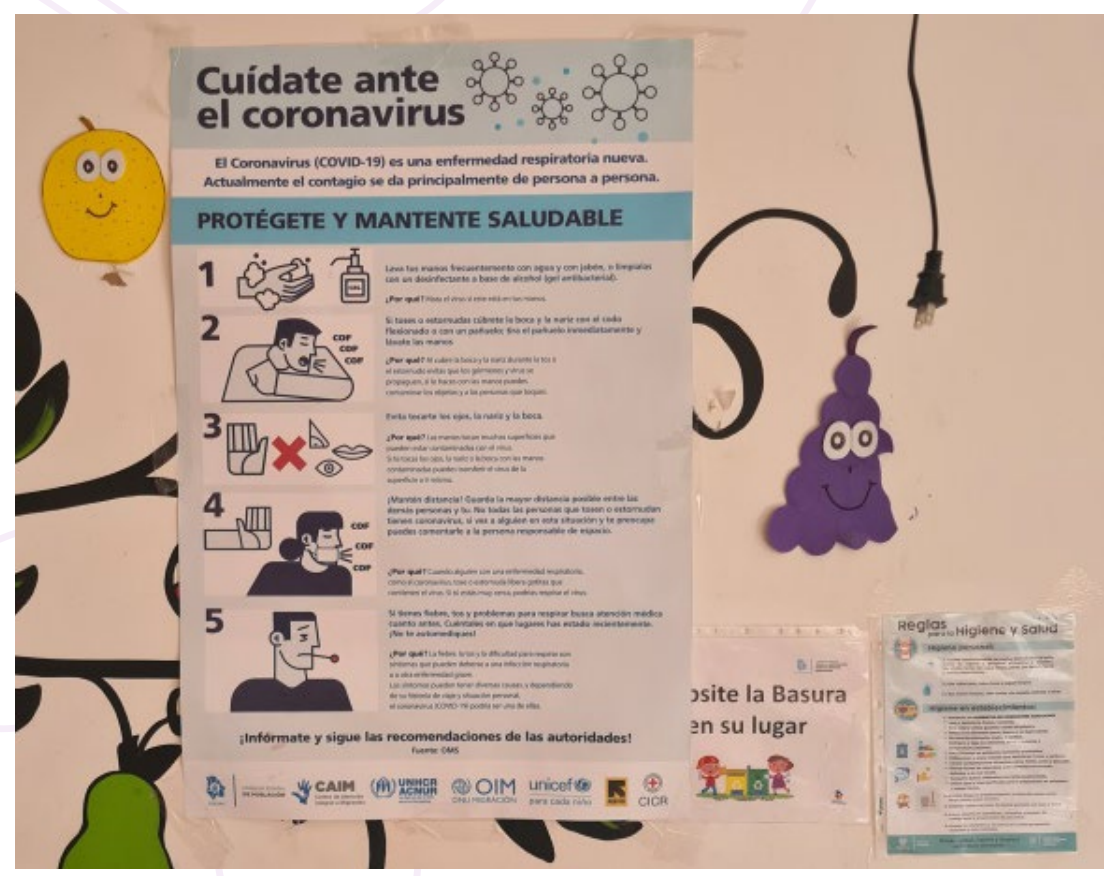

Fuente: Jesús Peña
A un $37.5 \%$ de las informantes le habían ofrecido alguna de las vacunas contra el COVID-19. Entre las personas a las que les habían ofrecido la vacuna, un $71 \%$ se vacunó. Un $74 \%$ se la pondría si se la ofrecieran. Por el contrario, un $28.9 \%$ rechazó la vacuna cuando se la ofrecieron y un $6 \%$ la rechazaría si se la ofrecieran. Un $20 \%$ esta indecisa sobre ponerse la vacuna si se la ofrecieran (ver cuadro 8). 
NECESIDADES Y ATENCIÓN EN SALUD SEXUAL Y

REPRODUCTIVA DE MUJERES MIGRANTES EN MÉXICO

Volumen 1

Cuadro 8. Distribución porcentual de casos y cuidados de Covid-19, 2021

\section{¿Usted o alguien que viva con usted ha tenido síntomas de COVID-19?}

Sí

Para las personas que sí tuvieron síntomas o alguien con quien vivía tuvo síntomas, ¿se hizo una prueba para ver si tenía COVID-19? ( $n=37)$

\begin{tabular}{ll}
\hline Sí & $78.4 \%$ \\
\hline Resultado positivo de las personas que sí se hicieron la prueba $(\mathbf{n}=9)$ & $31 \%$ \\
\hline ¿Si le ofrecieran la vacuna contra el COVID-19, se la pondría? (n=266) & \\
\hline Sí me la ofrecieron y ya me la puse & $71 \%$ \\
\hline Sí me la ofrecieron, pero no me la puse & $28.9 \%$ \\
\hline No me la han ofrecido, pero no sé si me la pondría & $20 \%$ \\
\hline No me la han ofrecido, pero sí me la pondría & $74 \%$ \\
\hline No me la han ofrecido, pero no me la pondría & $6 \%$ \\
\hline
\end{tabular}

Porcentaje

$14.2 \%$

Fuente: Elaboración propia

\subsection{Cuidados y preparación de SSR antes de iniciar su trayecto migratorio}

Antes de iniciar su viaje, 38.1\% $(n=102)$ de las mujeres encuestadas se colocó algún método anticonceptivo. Las encuestadas mencionaron seis tipos de métodos usados. El método más usado fue las inyecciones (ver cuadro 9). Las recomendaciones de qué método usar vinieron de una clínica u hospital (69.9\%), de un familiar (19.4\%) o de su pareja (5.4\%). El resto fue recomendado de otra fuente incluyendo otros migrante o dependencia de gobierno. El método usado lo obtuvieron de dos lugares principales: clínica u hospital (86.7\%) y en una farmacia (13.3\%). Un 90\% de las encuestadas eligió el método usado. Un 97.8\% señaló que el método elegido funcionó. 
NECESIDADES Y ATENCIÓN EN SALUD SEXUAL Y REPRODUCTIVA DE MUJERES MIGRANTES EN MÉXICO

Volumen 1

Cuadro 9. Distribución porcentual de métodos usados antes de iniciar viaje, 2021 (n=99)

\begin{tabular}{ll} 
Método usado & Porcentaje \\
\hline DIU o T Cobre & $4.1 \%$ \\
\hline Pastillas anticonceptivas & $7.1 \%$ \\
\hline Inyecciones & $55.6 \%$ \\
\hline Condón masculino & $1 \%$ \\
\hline Ligadura & $26.3 \%$ \\
\hline Espermicida & $1 \%$ \\
\hline
\end{tabular}

Nota: Pregunta permite respuesta de opción múltiple Fuente: Elaboración propia

A las mujeres que no se colocaron o prepararon algún método anticonceptivo antes de su viaje, se les preguntó la razón de no haberlo hecho. La gráfica $\mathbf{2}$ muestra los resultados. Destaca que un 41.9\%, no se colocó algún método porque no pensó en eso. Lo que sugiere que no lo consideraron como algo importante o necesario para su viaje.

Gráfica 2. Distribución porcentual de razones por las que no se colocó un método anticonceptivo antes de iniciar su viaje, $2021(n=161)$

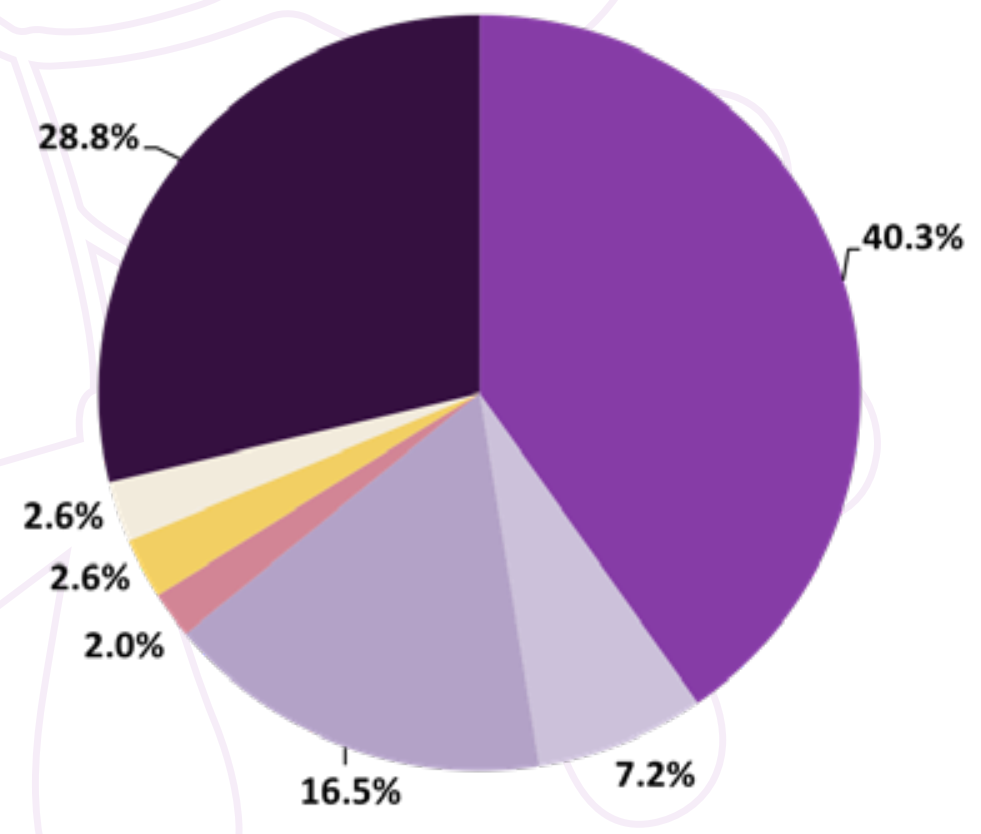

E Lo no pensó

No le dio tiempo

No tene pareja

Motivos religiosos

Pareja no está de acuerdo

Desconocimiento de los métodos o donde obtenerlos

- Otro motivo

Fuente: Elaboración propia 
Entre los datos captados por la respuesta "otro motivo", las de mayor mención fueron que hacen daño, no quería prevenir un embarazo, está operada y ya no puede tener hijos, y que ya estaba embarazada.

\subsection{Cuidados y problemas de SSR en el trayecto migratorio}

Con respecto a situaciones de SSR en el trayecto, se preguntó sobre situaciones vividas de salud menstrual. Un problema recurrente fue tener dolores constantes o en momentos que dificultaron sus actividades (62.2\%) y no haber tenido acceso a medicamentos para contrarrestar el dolor (ver cuadro 10).

Cuadro 10. Distribución porcentual de cuidados y problemas de salud menstrual en el trayecto por México, 2021

\begin{tabular}{llll}
\hline Tipo de problema & Siempre & A veces & Nunca \\
\hline Tuvo ciclo menstrual regular & $47.4 \%$ & $20.6 \%$ & $32 \%$ \\
\hline Tuvo suficientes paños limpios para limpiarse & $60 \%$ & $34.5 \%$ & $5.5 \%$ \\
\hline Tuvo suficientes toallas o tampones nuevos & $64.8 \%$ & $23.7 \%$ & $11.4 \%$ \\
\hline $\begin{array}{l}\text { Pudo cambiarse de toallas o tampones cada vez que } \\
\text { lo necesitó }\end{array}$ & $50.4 \%$ & $27.1 \%$ & $10.9 \%$ \\
\hline $\begin{array}{l}\text { Tuvo dolores que le dificultaron hacer sus actividades } \\
\text { durante su ciclo menstrual con dolor }\end{array}$ & $36.4 \%$ & $25.8 \%$ & $37.7 \%$ \\
\hline $\begin{array}{l}\text { Tuvo acceso a medicamentos para el dolor durante su } \\
\text { ciclo menstrual }\end{array}$ & $20.8 \%$ & $8.9 \%$ & $69.9 \%$ \\
\hline
\end{tabular}

Fuente: Elaboración propia 
NECESIDADES Y ATENCIÓN EN SALUD SEXUAL Y REPRODUCTIVA DE MUJERES MIGRANTES EN MÉXICO

Volumen 1

Foto 6. Alacena con artículos para prevención del Covid-19, medicamentos y productos para la salud menstrual, albergue Pan de Vida en Ciudad Juárez

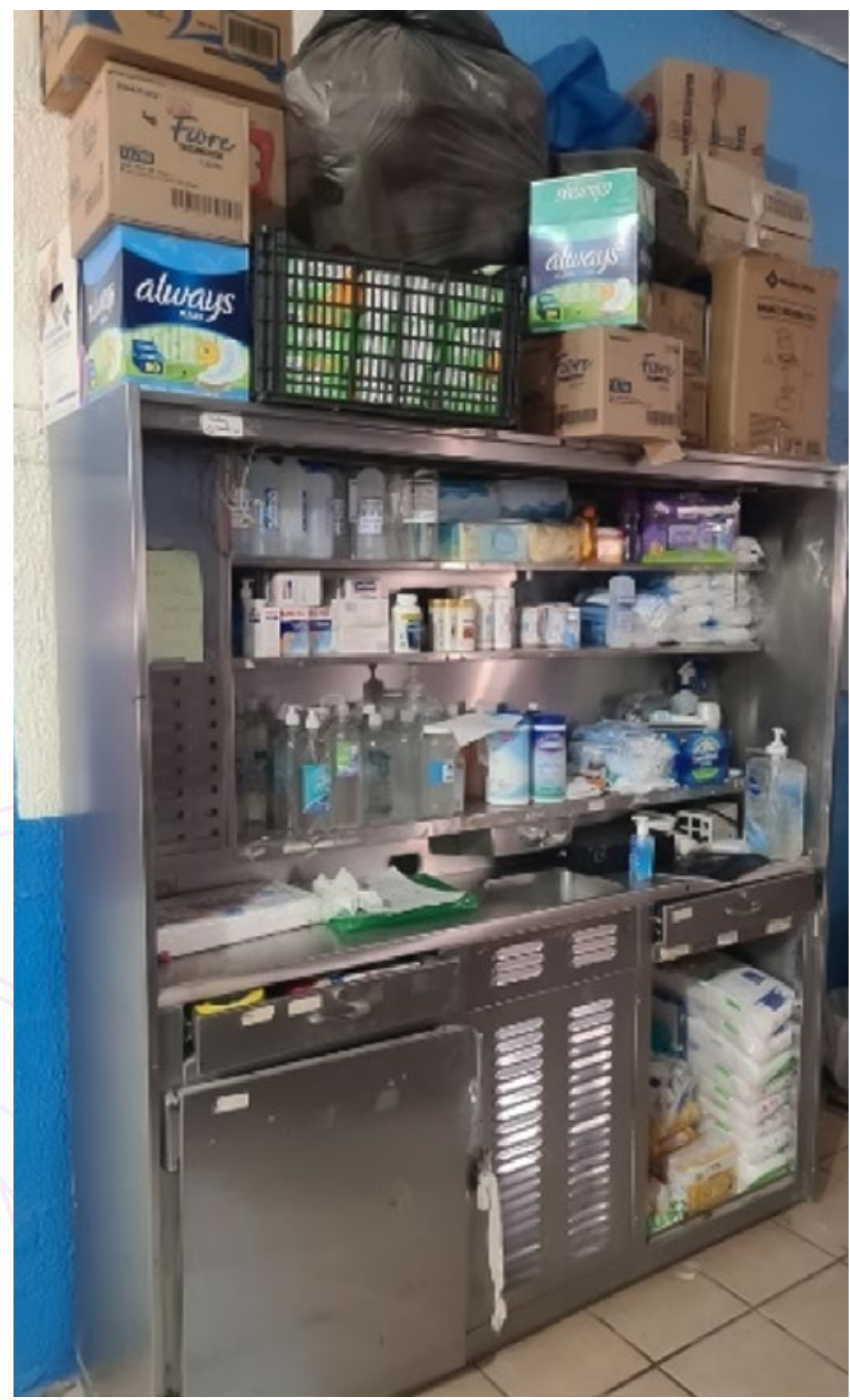


Sobre otros temas de SSR vividos en el trayecto, se les preguntó sobre problemas de salud en sus genitales. Sufrir dolor fue de nuevo un problema común (ver cuadro 11).

Cuadro 11. Distribución porcentual de cuidados y problemas de salud en el área genital durante el trayecto por México, 2021

\begin{tabular}{ll} 
Tipo de problema & Porcentaje que tuvo ese problema \\
\hline Sangrado diferente a la menstruación & $19.5 \%$ \\
\hline Verrugas & $6.6 \%$ \\
\hline Dolor & $33.1 \%$ \\
\hline Comezón & $24.5 \%$ \\
\hline Ronchas & $5.4 \%$ \\
\hline Problemas para orinar & $21 \%$ \\
\hline Flujo vaginal con mal olor & $18.7 \%$ \\
\hline Llagas & $2.7 \%$ \\
\hline
\end{tabular}

Nota: Pregunta permite respuesta de opción múltiple Fuente: Elaboración propia

Un 22.1\% de las mujeres que tuvieron uno o varios problema de salud en sus genitales buscó atención. Un 37.9\% la buscó en un hospital público y un $48.3 \%$ dentro del albergue donde se encontraba en esa parte de su viaje. El resto se atendió en consultorio de farmacia (10.3\%) en servicio médico privado (3.4\%) (ver gráfica 3).

Gráfica 3. Distribución porcentual de lugar donde se buscó la atención, 2021. ( $n=59)$

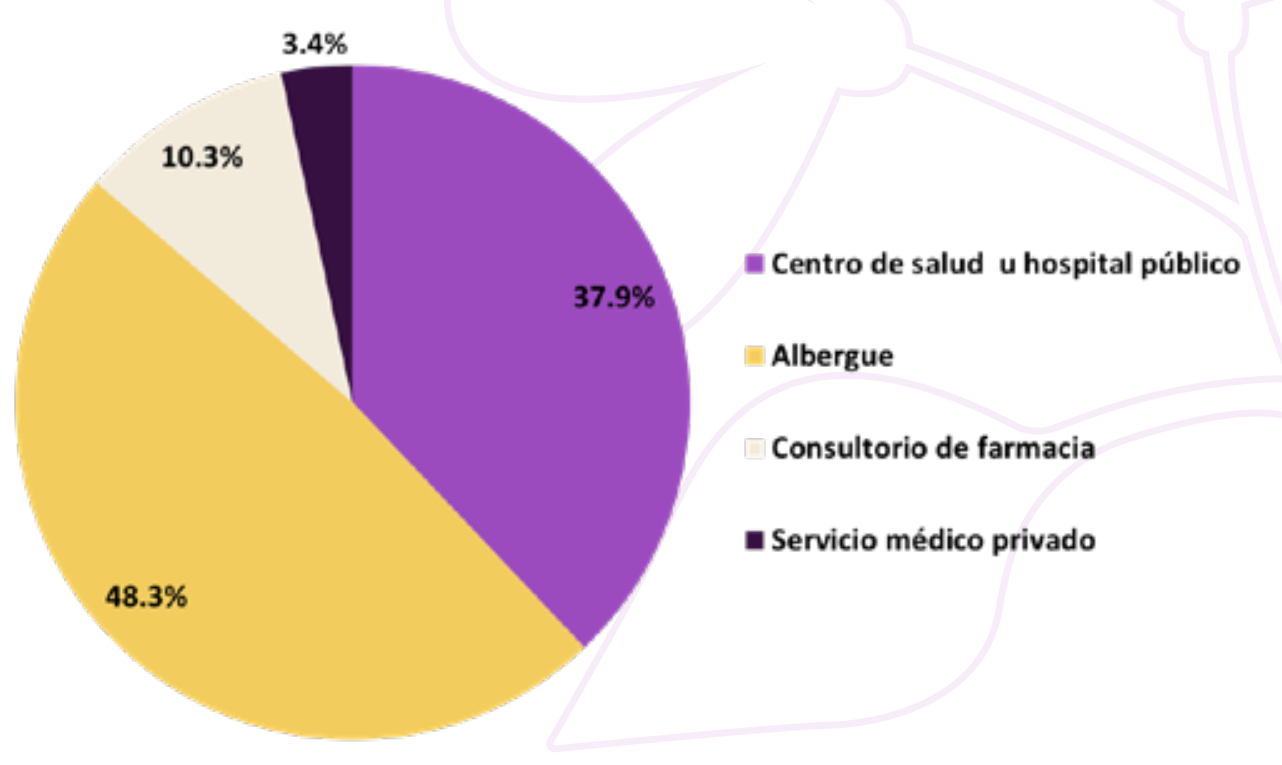


Un 82.1\% recibió la atención en el lugar donde la buscó. Con respecto al pago por la atención, 27.3\% tuvo que pagar para recibirla. Solamente una mujer encuestada declaró haber sentido que se refirieron a ella de forma inapropiada por el personal que la atendía. Ella considera que la razón fue su nacionalidad (Ver cuadro 12).

Cuadro 12. Distribución porcentual de situaciones vividas durante la atención recibida para atender su problema de salud en el área de los genitales durante el trayecto por México, 2021 $(n=59)$

\begin{tabular}{ll} 
Situación & Porcentaje \\
\hline Le explicaron sobre su padecimiento y el tratamiento & $77.3 \%$ \\
\hline Le dieron espacio para hacer preguntas & $72.7 \%$ \\
\hline Le hicieron un estudio socioeconómico para determinar el costo de la atención & $36.4 \%$ \\
\hline Esperó por largo tiempo a que la atendieran si darle explicación & $18.2 \%$ \\
\hline El personal fue siempre respetuoso & $95.5 \%$ \\
\hline La ignoraron cuando hizo preguntas o expresó preocupaciones & $4.5 \%$ \\
\hline Le dieron documentación explicando el tratamiento & $45.5 \%$ \\
\hline Le hicieron saber que estaban haciendo lo posible para cuidar de usted & $81.8 \%$ \\
\hline
\end{tabular}

Fuente: Elaboración propia

Las mujeres que buscaron atención y no la recibieron reportan que fue debido a que no había personal médico disponible. Al no recibir atención tuvieron que recurrir a la automedicación (38.6\%), sanación naturista o religiosa (4\%), buscaron otro lugar (4\%). El resto buscó otras maneras como asearse y bañarse o el problema se solucionó eventualmente (23.8\%). Un 29\% no pudo resolver su problema de salud.

Pasando a las mujeres que decidieron no buscar atención, fue en su mayoría debido a que no supieron a dónde ir (ver cuadro 13). Otra razón fue que no las dejaban salir del albergue en donde estaban; otras encuestadas se auto medicaron. Dos mujeres reportan que no buscaron atención porque la persona que contrataron para el traslado por México restringía su movilidad por medio de amenazas o a la fuerza. 
Cuadro 13. Distribución porcentual de las razones por las que no buscaron atención de su problema de salud en el área genital durante el trayecto por México, 2021

\begin{tabular}{ll} 
Razón & Porcentaje \\
No le dio importancia & $11.8 \%$ \\
\hline Prefirió seguir su camino & $13.7 \%$ \\
\hline No supo a dónde ir & $45.1 \%$ \\
\hline Miedo a que la identificaran como migrante & $5.9 \%$ \\
\hline Falta de dinero para transporte, consulta o medicamentos & $9.8 \%$ \\
\hline Le da vergüenza que la revisen & $3.9 \%$ \\
\hline No tenía quien le cuidara a sus hijos mientras buscaba atenderse & $1 \%$ \\
\hline Otra razón & $16.7 \%$ \\
\hline
\end{tabular}

La pregunta aceptaba múltiples respuestas. Fuente: Elaboración propia

Un $17 \%$ de la población encuestada tuvo relaciones sexuales durante su trayecto por México $(n=44)$. Se les preguntó si después de la relación habían tenido algún problema de salud sexual. El dolor en el vientre o abdomen fue el problema con más menciones (ver cuadro 14). Destaca que un 31.8\% estuvo preocupada por haber sido contagiada de alguna infección de transmisión sexual y un $34.1 \%$ por haber quedado embarazada.

Cuadro 14. Distribución porcentual problemas de salud después de haber tenido relaciones sexuales en durante el trayecto por México, $2021(n=44)$

\begin{tabular}{ll} 
Problema & Porcentaje \\
Heridas o lesiones en su vulva o vagina & $9.1 \%$ \\
\hline Dolor en su vientre o abdomen & $31.8 \%$ \\
\hline Dolor en el cuerpo & $18.2 \%$ \\
\hline Comezón, ronchas o mal olor en su vulva o vagina & $6.8 \%$ \\
\hline Preocupación por quedar embarazada & $34.1 \%$ \\
\hline Preocupación por haber sido contagiada de alguna enfermedad de transmisión sexual & $31.8 \%$ \\
\hline
\end{tabular}

Nota: Pregunta permite respuesta de opción múltiple Fuente: Elaboración propia 
Entre las que tuvieron algún problema después de tener relaciones sexuales, buscaron atención un $26.1 \%$. Un $16.7 \%$ lo hizo entre 1 a 7 días después de identificar un problema, de 8 a 15 días un $16,7 \%$, más de 15 días un 33.3\% y más de tres meses 33.3\%. Para su problema, buscaron atención en un centro de salud pública 50\%, 33.3\% en el albergue y un $16.7 \%$ en consultorio de farmacia. Todas recibieron atención donde la buscaron.

El cuadro 15 muestra situaciones vividas durante la atención recibida. Siendo el contagio de enfermedades de transmisión sexual una de las principales preocupaciones de las mujeres y el quedar embarazadas, desataca que solamente a un 33.3\% explicó sobre anticonceptivos de emergencia y a un 33.3\% se le habló sobre enfermedades de transmisión sexual. También sólo a un tercio se le ofreció atención psicológica. Un 83.3\% sintió que la estaban atendiendo lo mejor posible. En parte por eso, todas recomendarían el lugar donde se atendieron a otras mujeres migrantes.

Cuadro 15. Distribución porcentual de situaciones vividas durante la atención recibida por problemas de salud sexual después de tener relaciones sexuales durante el trayecto por México, 2021. $(n=44)$

\begin{tabular}{ll} 
Situación & Porcentaje \\
Le ofrecieron atención psicológica & $33.3 \%$ \\
\hline $\begin{array}{l}\text { Le explicaron sobre anticonceptivos de emergencia } \\
\text { Le informaron sobre riesgos de posibles infecciones de transmisión sexual y cómo } \\
\text { prevenirlas }\end{array}$ & $33.3 \%$ \\
\hline $\begin{array}{l}\text { Le ofrecieron profilaxis para prevenir la infección del VIH } \\
\text { Le permitieron hacer preguntas }\end{array}$ & $16.7 \%$ \\
\hline El trato fue siempre respetuoso & $66.7 \%$ \\
\hline La ignoraron cuando hizo preguntas o expresó preocupaciones & $100 \%$ \\
\hline Le dieron documentos explicando su padecimiento y el tratamiento a seguir & $16.7 \%$ \\
\hline Le hicieron saber que estaban haciendo lo posible para cuidar de usted & $66.7 \%$ \\
\hline Se refirieron a usted de forma inapropiada por su país de origen & $83.3 \%$ \\
\hline Se refirieron a usted de forma inapropiada por su color de piel & $16.7 \%$ \\
\hline Se refirieron a usted de forma inapropiada por su orientación sexual & $33.3 \%$ \\
\hline Pago por la atención recibida & $16.7 \%$ \\
\hline
\end{tabular}


Entre las mujeres que no buscaron atención, las razones principales fueron que no supo a dónde ir (41.2\%) y la falta de dinero para pagar la consulta, comprar medicina y el transporte al lugar (23.5\%). En otras razones se encuentra que no las dejaban salir del albergue y miedo y a ser identificada como migrante.

Con respecto al uso de métodos anticonceptivos durante el trayecto por México, se encontró que un $4.7 \%$ se colocó o usó algún método anticonceptivo. No obstante, si le sumamos a las mujeres que ya estaban usando un método antes de iniciar el viaje, el porcentaje de mujeres que viajaron por México usando algún método es del 44.3\% (ver gráfica 4).

Gráfica 4. Distribución porcentual de mujeres que se colocaron algún método anticonceptivo durante el trayecto por México, 2021

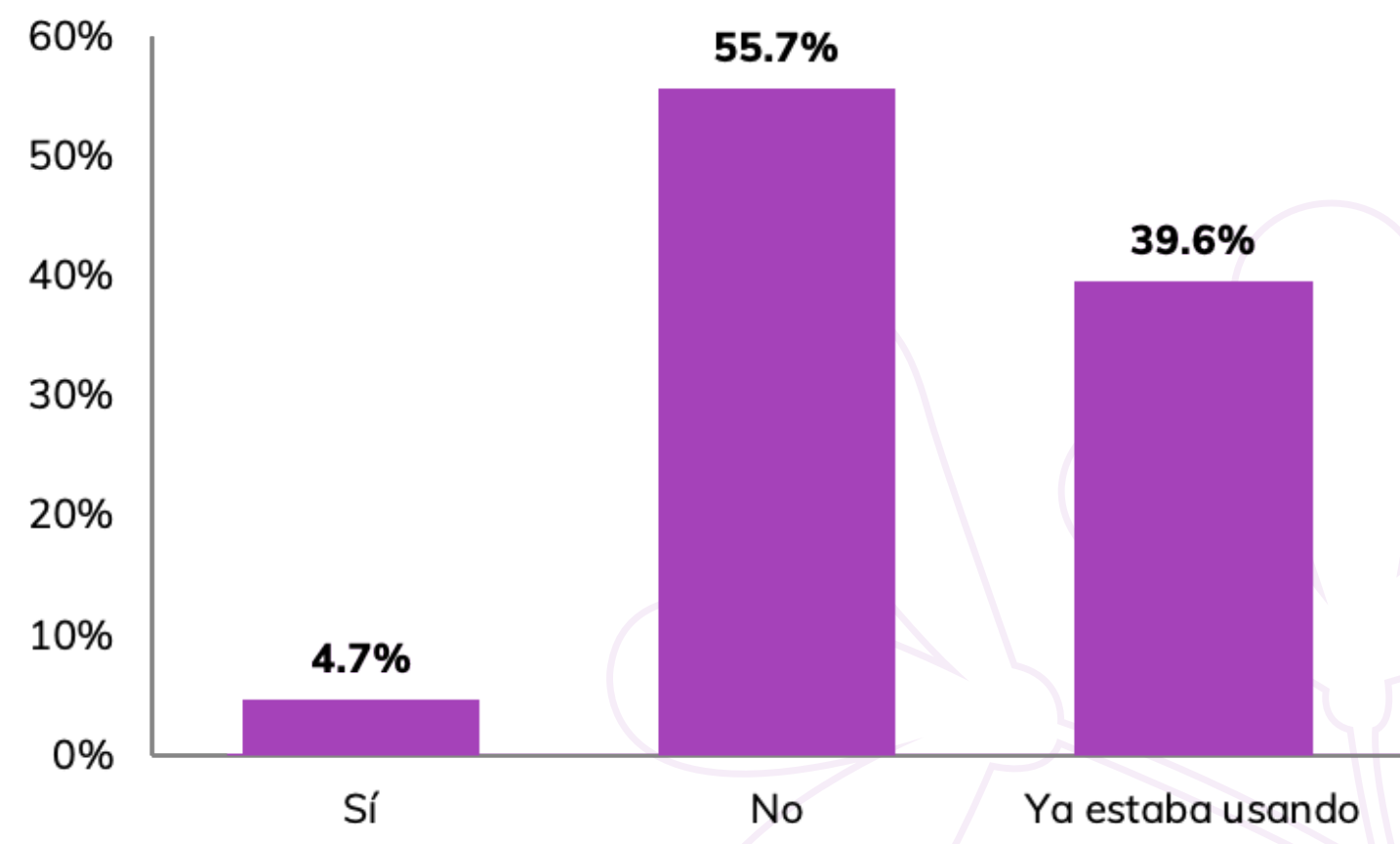

Fuente: Elaboración propia 
NECESIDADES Y ATENCIÓN EN SALUD SEXUAL Y REPRODUCTIVA DE MUJERES MIGRANTES EN MÉXICO

Volumen 1

Los métodos más utilizados fue el condón masculino y las inyecciones (ver cuadro 16). A un 66.7\% le brindaron el método en un centro de salud público, 8.3\% en un albergue, 25\% en una farmacia.

Cuadro 16. Distribución porcentual de método anticonceptivo usado durante el trayecto por México, 2021

\begin{tabular}{ll} 
Método usado & Porcentaje \\
\hline DIU o T Cobre & $16.7 \%$ \\
\hline Pastillas anticonceptivas & $16.7 \%$ \\
\hline Inyecciones & $25 \%$ \\
\hline Condón masculino & $25 \%$ \\
\hline Otro & $16.6 \%$ \\
\hline
\end{tabular}

Fuente. Elaboración propia 


\section{EMBARAZO}

\subsection{Cuidados del embarazo durante el trayecto por México}

Se encuestaron a 15 mujeres que estuvieron embarazadas durante su trayecto por México. Esta cifra representa el $4.7 \%$ de la población total encuestada. Esta población incluye a mujeres que estaban embarazadas al momento de salir de lugar de origen, así como las que se embarazaron durante el trayecto por México.

El cuadro 17, contiene un perfil de estas mujeres con nacionalidad, estado civil y número de hijos o hijas. Tres reportaron su estado civil como solteras. Todas tenían por lo menos un hijo/hija. La edad de las mujeres embarazadas tiene un rango de 44 años en el extremo superior, y la menor edad registrada fue en tres mujeres de 20 años.

Cuadro 17. Perfil de mujeres embarazadas durante el trayecto por México, 2021

\begin{tabular}{lllll} 
Perfil & Nacionalidad & Edad & Estado civil & Número de hijos/hijas \\
\hline 1 & Honduras & 28 & Casada & 2 \\
\hline 3 & Honduras & 32 & Unión libre & 2 \\
\hline 4 & Guatemala & 21 & Casada & 2 \\
\hline 5 & Honduras & 21 & Unión libre & 2 \\
\hline 6 & Honduras & 19 & Unión libre & 1 \\
\hline 7 & Guatemala & 25 & Unión libre & 3 \\
\hline 8 & Honduras & 28 & Casada & 2 \\
\hline 9 & Honduras & 21 & Unión libre & 1 \\
\hline 10 & Guatemala & 20 & Unión libre & 1 \\
\hline 11 & Honduras & 20 & Unión libre & 1 \\
\hline 12 & El Salvador & 20 & Unión libre & 1 \\
\hline 13 & Honduras & 20 & Unión libre & 1 \\
\hline 14 & Honduras & 44 & Soltera & 3 \\
\hline 15 & Honduras & 34 & Soltera & 2 \\
\hline
\end{tabular}

Fuente: Elaboración propia 
Con respecto a cuidados del embarazo, tres mujeres no buscaron la atención en servicios públicos de salud por falta de dinero o por no saber a dónde ir. Dos de ellas se atendieron en consultorios adyacentes a farmacias. En total dos tuvieron un aborto (no se especifica si inducido o espontáneo), aunque destaca que estas dos mujeres son parte de las tres respondientes que reportaron no haber buscado embarazarse. Por su parte, todas las mujeres que buscaron la atención fueron atendidas en algún centro de salud u hospital público. Nueve mujeres tuvieron el parto en el trayecto, es decir, en un lugar distinto a Ciudad Juárez. 


\section{NECESIDADES Y ATENCIÓN EN SALUD SEXUAL Y REPRODUCTIVA DE MUJERES MIGRANTES EN MÉXICO \\ Volumen 1}

Cuadro 18. Atención del embarazo durante el trayecto por México, 2021

\begin{tabular}{|c|c|c|c|c|c|c|}
\hline Perffl & $\begin{array}{l}\text { Quería } \\
\text { embarazarse }\end{array}$ & $\begin{array}{l}\text { Buscó } \\
\text { atención }\end{array}$ & $\begin{array}{l}\text { Recibió } \\
\text { atención para } \\
\text { cuidar del } \\
\text { embarazo }\end{array}$ & $\begin{array}{l}\text { Pagó con sus } \\
\text { recursos la } \\
\text { atención }\end{array}$ & $\begin{array}{l}\text { Sufrió } \\
\text { maltratos } \\
\text { durante la } \\
\text { atención }\end{array}$ & $\begin{array}{l}\text { Tuvo el parto } \\
\text { en el trayecto }\end{array}$ \\
\hline 1 & Sí & Sí & $\begin{array}{l}\text { Sí, en Centro de } \\
\text { salud público }\end{array}$ & No & No & No \\
\hline 2 & No & $\begin{array}{l}\text { No, por falta de } \\
\text { dinero }\end{array}$ & No se atendió & NA & NA & $\begin{array}{l}\text { No, tuvo un } \\
\text { aborto }\end{array}$ \\
\hline 3 & Sí & Sí & $\begin{array}{l}\text { Sí, en Clínica } \\
\text { particular }\end{array}$ & Sí & No & Sí \\
\hline 4 & Sí & Sí & $\begin{array}{l}\text { Sí, Centro de } \\
\text { Salud público }\end{array}$ & No & No & No \\
\hline 5 & Sí & Sí & $\begin{array}{l}\text { Sí, en Centro de } \\
\text { salud público }\end{array}$ & No & No & Sí \\
\hline 6 & Sí & Sí & Sí & No & No & Sí \\
\hline 7 & Sí & Sí & Sí & No & No & No \\
\hline 8 & No & $\begin{array}{l}\text { Sí, pero no } \\
\text { buscó en } \\
\text { servicios de } \\
\text { salud por falta } \\
\text { de dinero }\end{array}$ & $\begin{array}{l}\text { Se atendió en } \\
\text { un consultorio } \\
\text { de farmacia }\end{array}$ & Sí & NA & $\begin{array}{l}\text { No, tuvo un } \\
\text { aborto }\end{array}$ \\
\hline 9 & Sí & Sí & $\begin{array}{l}\text { Sí, en Centro de } \\
\text { salud público }\end{array}$ & No & No & Sí \\
\hline 10 & Sí & $\begin{array}{l}\text { Sí, pero no } \\
\text { buscó en } \\
\text { servicios de } \\
\text { salud por falta } \\
\text { de dinero }\end{array}$ & $\begin{array}{l}\text { Se atendió en } \\
\text { un consultorio } \\
\text { de farmacia }\end{array}$ & Sí & NA & Sí \\
\hline 11 & No & Sí & $\begin{array}{l}\text { Sí, en Centro de } \\
\text { salud público }\end{array}$ & No & No & No \\
\hline 12 & Sí & Sí & $\begin{array}{l}\text { Sí, en clínica } \\
\text { particular }\end{array}$ & Sí & No & Sí \\
\hline 13 & Sí & Sí & $\begin{array}{l}\text { Sí, en Centro de } \\
\text { salud público }\end{array}$ & No & No & Sí \\
\hline 14 & Sí & Sí & $\begin{array}{l}\text { Sí, en clínica } \\
\text { particular }\end{array}$ & Sí & No & Sí \\
\hline 15 & Sí & Sí & $\begin{array}{l}\text { Sí, en Centro de } \\
\text { salud público }\end{array}$ & No & No & Sí \\
\hline
\end{tabular}


De las mujeres que tuvieron el parto en el trayecto y respondieron las preguntas sobre la atención recibida $(n=8)$, tres se atendieron en una clínica privada, el resto en Centros de Salud u hospitales públicos. Se les hicieron preguntas acerca de la manera en que fueron atendidas y situaciones vividas durante la atención (ver cuadro 19). A cuatro de las mujeres les hicieron preguntas sobre su situación económica para determinar el costo de la atención (50\%). Cinco de ellas no tuvieron que pagar nada por la atención (62.5\%). Un problema experimentado por cinco mujeres también fue haber tenido que esperar por largo tiempo a ser atendidas sin que les explicaran la razón. Tres de las ocho mujeres que parieron en el trayecto (37.5\%) reportaron haber recibido comentarios que le parecieron ofensivos o humillantes. Esos comentarios fueron sobre su color de piel o apariencia. La evaluación global de la atención está divida. La mitad siente que el personal que la atendió hizo todo lo posible para cuidar de su salud. Sin embargo, solamente una mujer no recomendaría otra mujer migrante atenderse donde ella lo hizo.

Cuadro 19. Situaciones vividas durante la atención del parto.

\begin{tabular}{ll} 
Situación & Porcentaje (n=8)* \\
Le explicaron sobre el procedimiento que se llevaría a cabo & $75 \%$ \\
\hline Le dieron espacio para hacer preguntas & $50 \%$ \\
\hline La ignoraron cuando hizo preguntas o expresó preocupaciones & $50 \%$ \\
\hline Le hicieron un estudio socioeconómico para determinar el costo de la atención & $50 \%$ \\
\hline La atención fue sin ningún costo & $62.5 \%$ \\
\hline Tuvo que esperar largas horas para ser atendida sin que le dieran explicación & $62.5 \%$ \\
\hline Le gritaron o regañaron & $22.2 \%$ \\
\hline Le dijeron cosas ofensivas o humillantes & $37.5 \%$ \\
\hline Se refirieron a usted de forma inapropiada por su país de origen & $12.5 \%$ \\
\hline Se refirieron a usted de forma inapropiada por su forma de hablar & $0 \%$ \\
\hline Se refirieron a usted de forma inapropiada por su color de piel & $25 \%$ \\
\hline Se refirieron a usted de forma inapropiada por su apariencia & $25 \%$ \\
\hline Se refirieron a usted de forma inapropiada por su orientación sexual & $0 \%$ \\
\hline El personal médico fue siempre respetuoso & $62.5 \%$ \\
\hline Le dieron instrucciones impresas explicando el tratamiento después del parto & $50 \%$ \\
\hline Le hicieron saber que estaban haciendo todo lo posible para cuidar de usted & $50 \%$ \\
\hline Recomendaría a otra mujer migrante atenderse donde usted lo hizo & $87.5 \%$ \\
\hline
\end{tabular}


Todas las mujeres embarazadas durante el trayecto reportaron haber tenido preocupación por no tener dinero, situación que concuerda con no haber buscado atención en los tres casos mencionados. En relación con el total de la población encuestada, las mujeres embarazadas tuvieron mayor preocupación por no tener qué comer o beber (ver cuadro 20). De manera similar, este grupo reporta haber sufrido en mayor proporción violencia física (60\%) y amenazas o intimidación (80\%) que el total de las encuestadas ( $20.1 \%$ y $42.4 \%$ respectivamente).

Cuadro 20. Distribución porcentual de situaciones vividas en México por mujeres que estaban embarazadas durante el trayecto por ese país, 2021

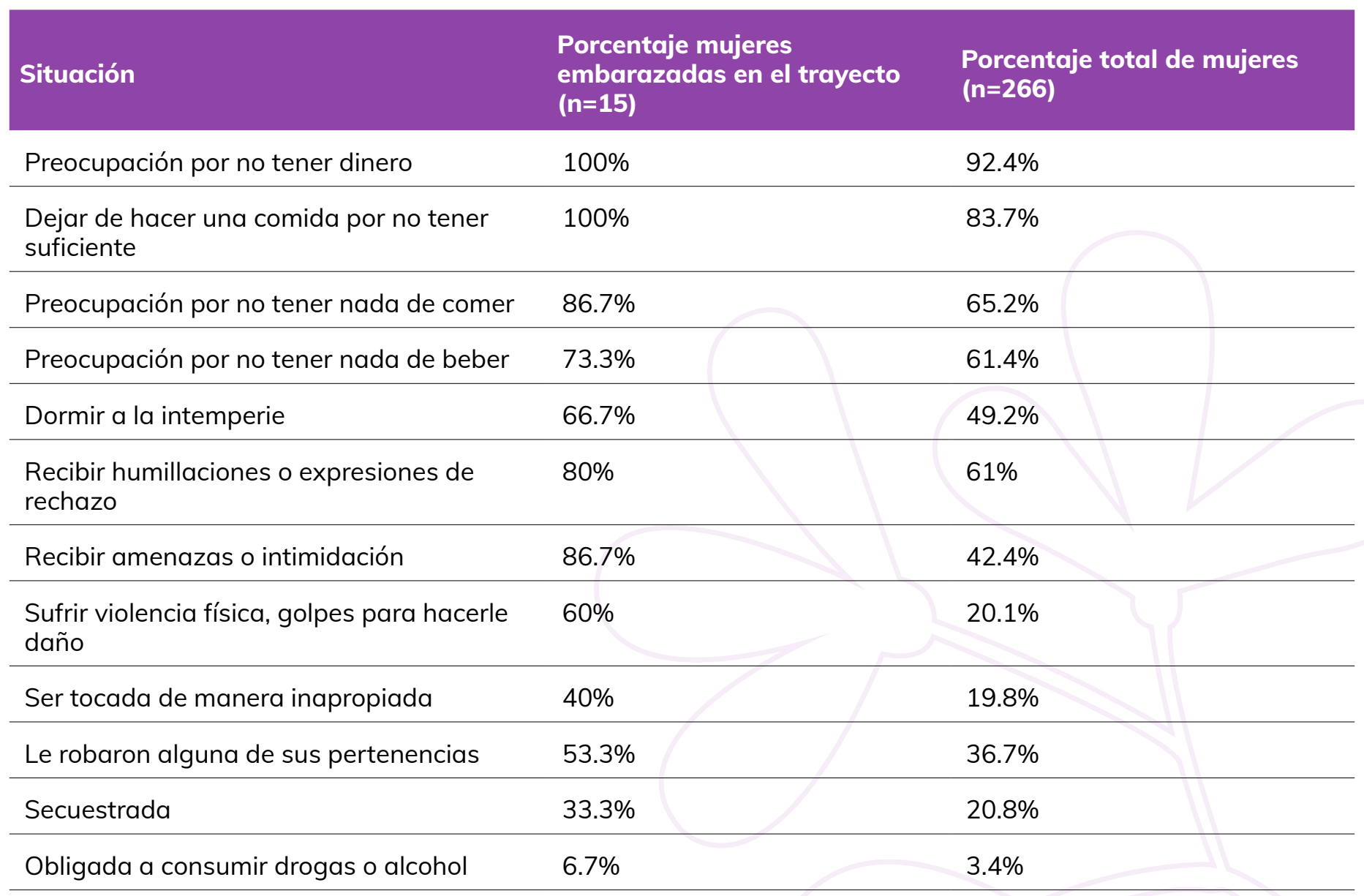

Fuente: Elaboración propia 


\subsection{Cuidados del embarazo en Ciudad Juárez}

Se encuestaron a cuatro mujeres que estaban embarazadas al momento de responder la encuesta, lo que representa el $1.5 \%$ de la población total encuestada. Se trata de mujeres por debajo de los 30 años, con por lo menos un hijo o hija. El embarazo más avanzado era de 42 semanas y el menos avanzado de 10 semanas. Solamente una encuestada expresó que no buscaba embarazarse. Todas viajaban acompañadas de su pareja o hijos o hijas, quienes también se encontraban en Ciudad Juárez (ver cuadro 21).

Cuadro 21. Perfil de mujeres embarazadas al momento de contestar la encuesta

\begin{tabular}{|c|c|c|c|c|c|c|c|}
\hline Perfil & Nacionalidad & Edad & $\begin{array}{l}\text { Semanas de } \\
\text { embarazo }\end{array}$ & $\begin{array}{l}\text { Buscaba } \\
\text { embarazarse }\end{array}$ & $\begin{array}{l}\text { Número de } \\
\text { Hijos/Hijas }\end{array}$ & $\begin{array}{l}\text { Quien la } \\
\text { acompaña en } \\
\text { Ciudad Juárez }\end{array}$ & $\begin{array}{l}\text { Tiempo en } \\
\text { Ciudad Juárez }\end{array}$ \\
\hline 1 & Honduras & 28 & 42 & Sí & 2 & $\begin{array}{l}\text { Hijos/hijas y } \\
\text { pareja }\end{array}$ & 15 días \\
\hline 2 & Honduras & 20 & 17 & Sí & 1 & $\begin{array}{l}\text { Hijos/hijas y } \\
\text { pareja }\end{array}$ & 2 meses \\
\hline 3 & Honduras & 24 & 10 & Sí & 1 & $\begin{array}{l}\text { Hijos/hijas y } \\
\text { pareja }\end{array}$ & 1 día \\
\hline 4 & El Salvador & 24 & 26 & No & 2 & $\begin{array}{l}\text { Hijos/hijas y } \\
\text { pareja }\end{array}$ & 11 días \\
\hline
\end{tabular}

Fuente: Elaboración propia

De acuerdo con el reporte de las mujeres entrevistadas, en general llevaban poco tiempo en Ciudad Juárez, una tenía un día en la ciudad, por lo que no es de extrañar que no hubieran buscado atención al momento de ser encuestadas. No obstante, una encuestada señalo preocupación por no tener dinero para poder atenderse. De manera similar, otra mujer tenía preocupación por no encontrar atención, pero esta vez debido a que requiere de un tratamiento médico especializado por padecer 4 fibromas uterinos. Las dos encuestas que sí buscaron atención tenían más de 14 días en Ciudad Juárez. Las dos buscaron y obtuvieron atención en centros de salud públicos de manera gratuita. Ninguna reporta maltratos o situaciones incomodas durante la atención debido a su nacionalidad, color de piel, por ser migrante, su cuerpo o su orientación sexual (ver cuadro 22). 
Cuadro 22. Atención durante el embarazo

\begin{tabular}{|c|c|c|c|c|c|c|}
\hline Perfil & $\begin{array}{l}\text { Buscó } \\
\text { atención para } \\
\text { su embarazo }\end{array}$ & $\begin{array}{l}\text { Recibió } \\
\text { atención }\end{array}$ & $\begin{array}{l}\text { Lugar donde } \\
\text { fue atendida }\end{array}$ & $\begin{array}{l}\text { Pagó con sus } \\
\text { recursos la } \\
\text { atención }\end{array}$ & $\begin{array}{l}\text { Sufrió } \\
\text { maltratos } \\
\text { durante la } \\
\text { atención }\end{array}$ & $\begin{array}{l}\text { Le gustaría } \\
\text { atendida } \\
\text { durante el } \\
\text { parto por }\end{array}$ \\
\hline 1 & Sí & Sí & $\begin{array}{l}\text { Centro de salud } \\
\text { u hospital } \\
\text { público }\end{array}$ & No & No & Médico mujer \\
\hline 2 & Sí & Sí & $\begin{array}{l}\text { Unidad móvil } \\
\text { de salud dentro } \\
\text { del albergue }\end{array}$ & No & No & $\begin{array}{l}\text { No tiene } \\
\text { preferencia }\end{array}$ \\
\hline 3 & $\begin{array}{l}\text { No, tiene un día } \\
\text { en la ciudad }\end{array}$ & $\begin{array}{l}\text { No tuve dinero } \\
\text { para atención } \\
\text { cuando la } \\
\text { busqué }\end{array}$ & NA & NA & NA & Médico hombre \\
\hline 4 & No & N/A & $\begin{array}{l}\text { Necesita } \\
\text { atención } \\
\text { especial y no } \\
\text { sabe a dónde } \\
\text { ir. Tiene un } \\
\text { fibroma uterino }\end{array}$ & N/A & N/A & Médico mujer \\
\hline
\end{tabular}

Fuente: Elaboración propia

\subsection{Planes de embarazo}

Se les preguntó a las mujeres encuestadas que no estaban embarazadas si querían o estaban buscando embarazarse desde su llegada a Ciudad Juárez. Los datos obtenidos señalan que muy pocas mujeres deseaban o estaban buscando embazarse (ver gráfica 5). No obstante, solamente $37.3 \%$ del total de la población encuestada estaba usando algún método anticonceptivo y un 17.8\% usó condón masculino en su última relación sexual. Dentro de este porcentaje se debe incluir a las mujeres que no estaban teniendo relaciones sexuales por no tener pareja o vida sexual activa (60\%), por lo que no vieron la necesidad de usar métodos anticonceptivos. A estas mujeres, se les suman las que consideran que ya no están en edad reproductiva y las que tienen pareja de su mismo sexo. No obstante, se puede inferir que una proporción importante de mujeres que no busca embazarse no estaba usando algún método anticonceptivo. Entre las mujeres que sí estaban usando algún método, el más usado fueron las inyecciones (ver cuadro 23). 


\section{NECESIDADES Y ATENCIÓN EN SALUD SEXUAL Y REPRODUCTIVA DE MUJERES MIGRANTES EN MÉXICO}

Gráfica 5. Distribución porcentual de mujeres encuestadas según su deseo de querer en la actualidad querían o estaban buscando embarazarse y uso de método anticonceptivo en la actualidad, 2021( $n=266)$

¿Actualmente, quiere o está buscando embarazarse?

$96.0 \%$

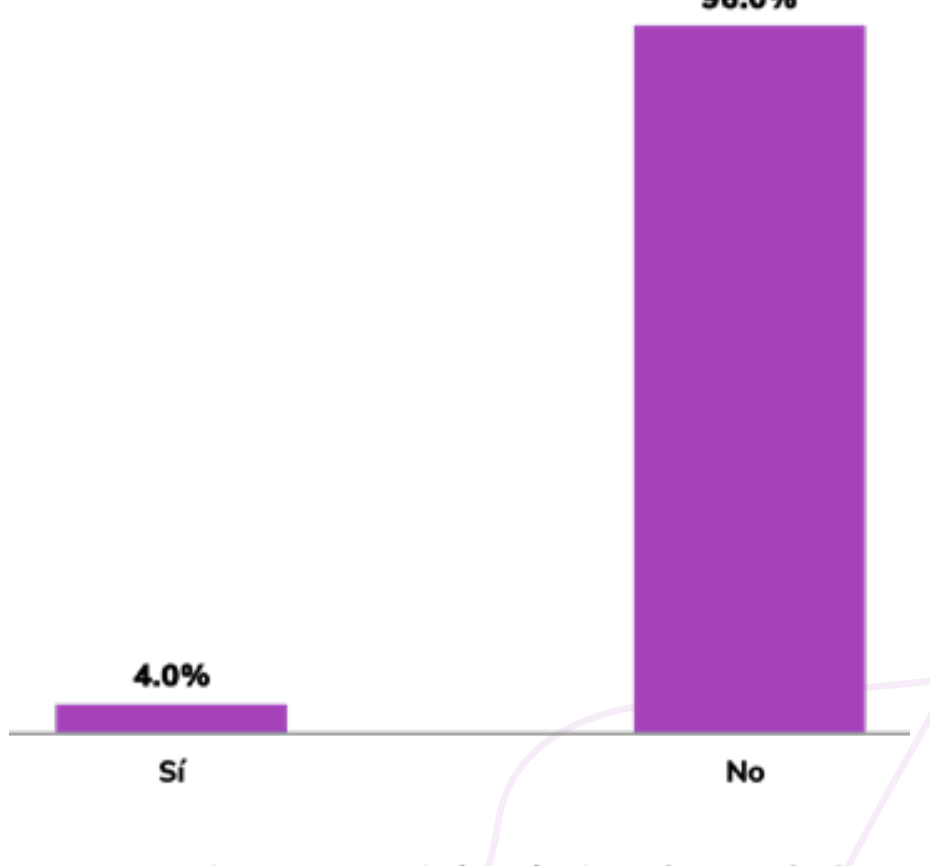

Actualmente, ¿usa algún método anticonceptivo?
Cuadro 23. Distribución porcentual de método anticonceptivo usado en la actualidad, 2021

$$
(n=98)
$$

\begin{tabular}{ll}
$\begin{array}{l}\text { Método anticonceptivo que está } \\
\text { usando en la actualidad }\end{array}$ & Porcentaje \\
\hline DIU/T Cobre & $6.1 \%$ \\
\hline Pastillas & $2 \%$ \\
\hline Inyecciones & $38.8 \%$ \\
\hline Condón masculino & $5.1 \%$ \\
\hline Operación & $37.8 \%$ \\
\hline Otro & $10.2 \%$ \\
\hline
\end{tabular}

Fuente: Elaboración propia

Cuadro 24. Distribución porcentual de razón por la que no están usado algún método anticonceptivo en la actualidad, 2021 ( $n=165$ )

\begin{tabular}{|c|c|}
\hline Razón & Porcentaje \\
\hline $\begin{array}{l}\text { No tiene pareja sexual / no está } \\
\text { teniendo relaciones sexuales }\end{array}$ & $60 \%$ \\
\hline Hacen daño o no le gusta usarlos & $7 \%$ \\
\hline Motivos religiosos o morales & $2.1 \%$ \\
\hline Su pareja no está de acuerdo & $2.8 \%$ \\
\hline Desconoce cómo usarlos & $4.9 \%$ \\
\hline No tiene dinero para comprarlos & $8.5 \%$ \\
\hline Otro & $14.7 \%$ \\
\hline
\end{tabular}




\section{OPINIONES Y CONOCIMIENTO SOBRE SSR}

\subsection{Conocimientos generales sobre SSR}

Para indagar acerca de los conocimientos de las mujeres encuestadas sobre aspectos de la SSR, se les presentaron una serie de enunciados a los cuales podrían responder como verdadero, falso o no sabe. El cuadro 25 muestra los resultados. Destacan los altos porcentajes de respuestas de no sabe en preguntas sobre el uso del tampón, medicamentos para evitar el contagio del VIH y sobre el uso de métodos para evitar un embarazo o interrumpirlo de forma segura con medicamentos. Otro resultado a destacar es que más de la mitad de las encuestadas (55\%) considera que una violación la comete una persona desconocida, y que el 75.4\% considera que una violación sexual siempre está acompañada de violencia física (ver cuadro 25).

Para poner en perspectiva el nivel de conocimiento de las mujeres encuestadas, por medio de la técnica de bola de nieve, se les aplicó un cuestionario vía telefónica con las mismas preguntas a 21 mujeres de nacionalidad mexicana con estudios de licenciatura en adelante y que no se encontraban en situación de movilidad. Sus respuestas aparecen en el cuadro 25 identificadas como "mujeres mexicanas no migrantes". Esta encuesta no buscó representatividad estadística alguna. Se limita a un ejercicio para establecer un punto de comparación entre dos poblaciones de mujeres con características y en condiciones diferentes que permita dar contexto a las respuestas de las mujeres migrantes encuestadas. Destaca las diferencias en conocimiento sobre salud menstrual. Un $100 \%$ de las mujeres mexicanas encuestadas considera que un tampón no puede usarse más de un día sin riesgos a la salud, mientras que un $42 \%$ de las mujeres migrantes no están seguras de eso y un $52.3 \%$ dice que es falso. Otro resultado comparativo interesante es sobre las perspectivas sobre violencia sexual. Un 100\% de las mexicanas encuestadas contestó que era falso que una violación siempre ocurre por una persona desconocida, mientras que en las mujeres migrantes fue del $36.1 \%$ y un $8.4 \%$ contestó no saber. Adicionalmente, un $75.4 \%$ de las mujeres migrantes contestó que era verdadero que una violación sexual siempre ocurre con violencia física; en las mujeres mexicanas fue del 19\%. Sobre enfermedades de trasmisión sexual, existe un alto porcentaje de mujeres en ambos grupos que no sabe si la hepatitis B se puede contagiar por relaciones sexuales. Un 39\% de las mujeres migrantes no lo sabe al igual que un $28.7 \%$ de las mexicanas. En temas sobre la interrupción del embarazo, se encontró similitudes en las respuestas sobre métodos. Un $31.4 \%$ de las mujeres migrantes consideran como verdadero que hay pastillas que provocan un aborto sin dañar la salud de la mujer; en las mujeres mexicanas fue del $\mathbf{4 7 . 6 \%}$. Vale la pena señalar que un $13.5 \%$ de las mujeres mexicanas no sabe sobre la existencia o el efecto de esas pastillas. 


\section{NECESIDADES Y ATENCIÓN EN SALUD SEXUAL Y REPRODUCTIVA DE MUJERES MIGRANTES EN MÉXICO}

Volumen 1

\section{Cuadro 25. Distribución porcentual de respuestas a enunciados} sobre salud sexual y productiva, 2021

\begin{tabular}{|c|c|c|c|}
\hline Enunciado & Verdadero & Falso & No sabe \\
\hline Un tampón puede usarse más de un día sin ningún riesgo a la salud & $5.7 \%$ & $52.3 \%$ & $42 \%$ \\
\hline Mujeres mexicanas no migrantes & $0 \%$ & $100 \%$ & $0 \%$ \\
\hline Hay días en los que una mujer tiene más posibilidades de quedar embarazada & $81.1 \%$ & $5.7 \%$ & $13.2 \%$ \\
\hline Mujeres no migrantes & $100 \%$ & $0 \%$ & $0 \%$ \\
\hline Si se lava bien, un condón se puede usar más de una vez & $2 \%$ & $93.4 \%$ & $4.5 \%$ \\
\hline Mujeres mexicanas no migrantes & $0 \%$ & $100 \%$ & $0 \%$ \\
\hline El uso del condón es un método eficaz para prevenir la transmisión del VIH & $65 \%$ & $23.1 \%$ & $11.9 \%$ \\
\hline Mujeres mexicanas no migrantes & $90.4 \%$ & $4.8 \%$ & $4.8 \%$ \\
\hline $\begin{array}{l}\text { Si una persona tiene relaciones sexuales sin protección, puede tomar } \\
\text { medicamentos en los tres primeros días para prevenir el contagio del VIH }\end{array}$ & $17 \%$ & $41.3 \%$ & $41.7 \%$ \\
\hline Mujeres mexicanas no migrantes & $66.7 \%$ & $23.8 \%$ & $9.5 \%$ \\
\hline La gonorrea es una enfermedad de transmisión sexual & $72.3 \%$ & $4.5 \%$ & $23.2 \%$ \\
\hline Mujeres mexicanas no migrantes & $100 \%$ & $0 \%$ & $0 \%$ \\
\hline La hepatitis B es una enfermedad de transmisión sexual & $38.3 \%$ & $22.7 \%$ & $39 \%$ \\
\hline Mujeres mexicanas no migrantes & $57.1 \%$ & $14.3 \%$ & $28.6 \%$ \\
\hline El hombre necesita las relaciones sexuales más que la mujer & $59.8 \%$ & $14 \%$ & $26.2 \%$ \\
\hline Mujeres mexicanas no migrantes & $0 \%$ & $100 \%$ & $0 \%$ \\
\hline Una violación siempre ocurre por una persona desconocida & $55.4 \%$ & $36.1 \%$ & $8.4 \%$ \\
\hline Mujeres mexicanas no migrantes & $0 \%$ & $100 \%$ & $0 \%$ \\
\hline Una violación siempre ocurre con violencia física & $75.4 \%$ & $15.2 \%$ & $9.4 \%$ \\
\hline Mujeres mexicanas no migrantes & $19 \%$ & $81 \%$ & $0 \%$ \\
\hline $\begin{array}{l}\text { La píldora del día siguiente se debe tomar dentro de los primeros tres días } \\
\text { después de haber tenido relaciones sexuales sin protección para prevenir un } \\
\text { embarazo }\end{array}$ & $39 \%$ & $21.6 \%$ & $39.4 \%$ \\
\hline Mujeres mexicanas no migrantes & $76.2 \%$ & $23.8 \%$ & $0 \%$ \\
\hline La píldora del día siguiente es abortiva & $41.3 \%$ & $18.9 \%$ & $39.8 \%$ \\
\hline Mujeres mexicanas no migrantes & $9.5 \%$ & $80.9 \%$ & $9.5 \%$ \\
\hline Hay pastillas que provocan un aborto y no dañan a la mujer & $31.4 \%$ & $28.8 \%$ & $39.8 \%$ \\
\hline Mujeres mexicanas no migrantes & $47.6 \%$ & $38.9 \%$ & $13.5 \%$ \\
\hline $\begin{array}{l}\text { Es seguro para la salud de la mujer provocar un aborto tomando té de canela o } \\
\text { de cilantro }\end{array}$ & $14.4 \%$ & $47.3 \%$ & $38.3 \%$ \\
\hline Mujeres mexicanas no migrantes & $0 \%$ & $90.5 \%$ & $9.5 \%$ \\
\hline
\end{tabular}




\subsection{Conocimiento sobre derechos de salud y acceso a atención de población migrante extranjera en México}

Partiendo de una hipótesis que la falta de conocimiento sobre acceso a servicios por parte de las poblaciones usuarias para buscar atención, la sexta sección de la encuesta estuvo dedicada a medir las opiniones y conocimiento de las mujeres migrantes sobre su derecho a la salud en México. Se encontró que un $\mathbf{1 9 . 2 \%}$ de las encuestadas considera que las mujeres migrantes sin documentos no tienen derecho a la salud en México. Otro $16.5 \%$ no está segura o no sabe. No obstante, un poco más de la mitad considera que una migrante sin documentos puede ir a un hospital y ser atendida (ver cuadro 26).

Cuadro 26. Distribución porcentual de conocimiento sobre el derecho a la salud de mujeres migrantes sin documentos migratorios en México, 2021.

De acuerdo con lo que usted sabe, ¿Las migrantes que viajan sin papeles tienen derecho a la salud en México?

Sí

No

No sabe/ No está segura

De acuerdo con lo que usted ha vivido, ¿las migrantes que viaja por México sin papeles pueden ir a una clínica u hospital y ser atendidas?

\begin{tabular}{ll}
\hline Sí & $52.6 \%$ \\
\hline No & $24.1 \%$ \\
\hline No sabe & $23.3 \%$ \\
\hline
\end{tabular}

Fuente: Elaboración propia
Porcentaje

$64.3 \%$

$19.2 \%$

$16.5 \%$

Porcentaje

$52.6 \%$

$23.3 \%$

Otras preguntas fueron enfocadas al acceso a la interrupción del embarazo. Llama la atención, los altos porcentajes de mujeres que desconocen si en caso de violación pueden solicitar atención sin sufrir algún castigo o ser deportadas (ver cuadro 27). Resaltan los altos porcentajes en las respuestas de no sabe. Lo que siguiere que muchas mujeres no buscarían atención después de una violación. 
Cuadro 27. Distribución porcentual de opiniones sobre acceso a servicios de SSR de mujeres migrantes, 2021

\section{Enunciado}

Verdadero Falso

No sabe

Si una mujer migrante es violada y queda embarazada,

$24.6 \%$

$19.3 \%$

$56.1 \%$

puede pedir un aborto en un hospital público y no ser

castigada por ello.

Si una mujer migrante es violada, puede pedir un aborto $\quad 22 \%$

$31.4 \%$

$53.4 \%$ en un hospital público sin necesidad de denunciar la violación.

Las mujeres migrantes podemos acudir a una clínica u hospital público y ser atendidas sin temor a que nos

$48.3 \%$

$21.3 \%$

$30.4 \%$ deporten

Otro aspecto que en el que se recabaron datos fue el acceso a atención y cuidados de SSR durante el trayecto para una mujer migrante. Los resultados indican que la mayoría de las mujeres considera difícil atender su SSR en el trayecto incluyendo su salud menstrual. Con respecto al embarazo, a un 35.3\% les parece fácil evitar un embarazo. Sin embargo, atender un parto y los cuidados después de un parto están consideradas entre las situaciones de SSR más difíciles de atender (ver cuadro 28).

Cuadro 28. Distribución porcentual de opinión sobre atención de SSR de mujeres migrantes en el trayecto por México, 2021

\begin{tabular}{llll} 
Situación & Fácil & Difícil & No sabe \\
\hline Atender infecciones de transmisión sexual & $13.2 \%$ & $77.5 \%$ & $9.3 \%$ \\
\hline Prevenir infecciones de transmisión sexual & $28.7 \%$ & $64 \%$ & $7.4 \%$ \\
\hline Atender su salud menstrual & $17.8 \%$ & $77.9 \%$ & $4.3 \%$ \\
\hline Evitar un embarazo & $35.3 \%$ & $58.9 \%$ & $5.8 \%$ \\
\hline Atender un parto & $7 \%$ & $82.9 \%$ & $10.1 \%$ \\
\hline Cuidados después de un parto & $8.9 \%$ & $86.4 \%$ & $4.7 \%$ \\
\hline Interrumpir un embarazo & $5.4 \%$ & $86 \%$ & $8.1 \%$ \\
\hline Cuidar de su salud en caso de una violación & $6.2 \%$ & $86.4 \%$ & $7.4 \%$ \\
\hline
\end{tabular}

Fuente: Elaboración propia 

SSR

En la sección final de la encuesta, se hicieron preguntas con la finalidad de hacer una valoración de su experiencia migratoria hasta el momento en temas de SSR. Se les preguntó sobre la etapa en la que tuvieron mayores necesidades de SSR. Un 48.85\% respondió que fue en el trayecto por Mexico la etapa en la que más tuvieron necesidades (ver gráfica 6).

Gráfica 6. Distribución porcentual de valoración de necesidades de SSR en la experiencia migratoria, 2021

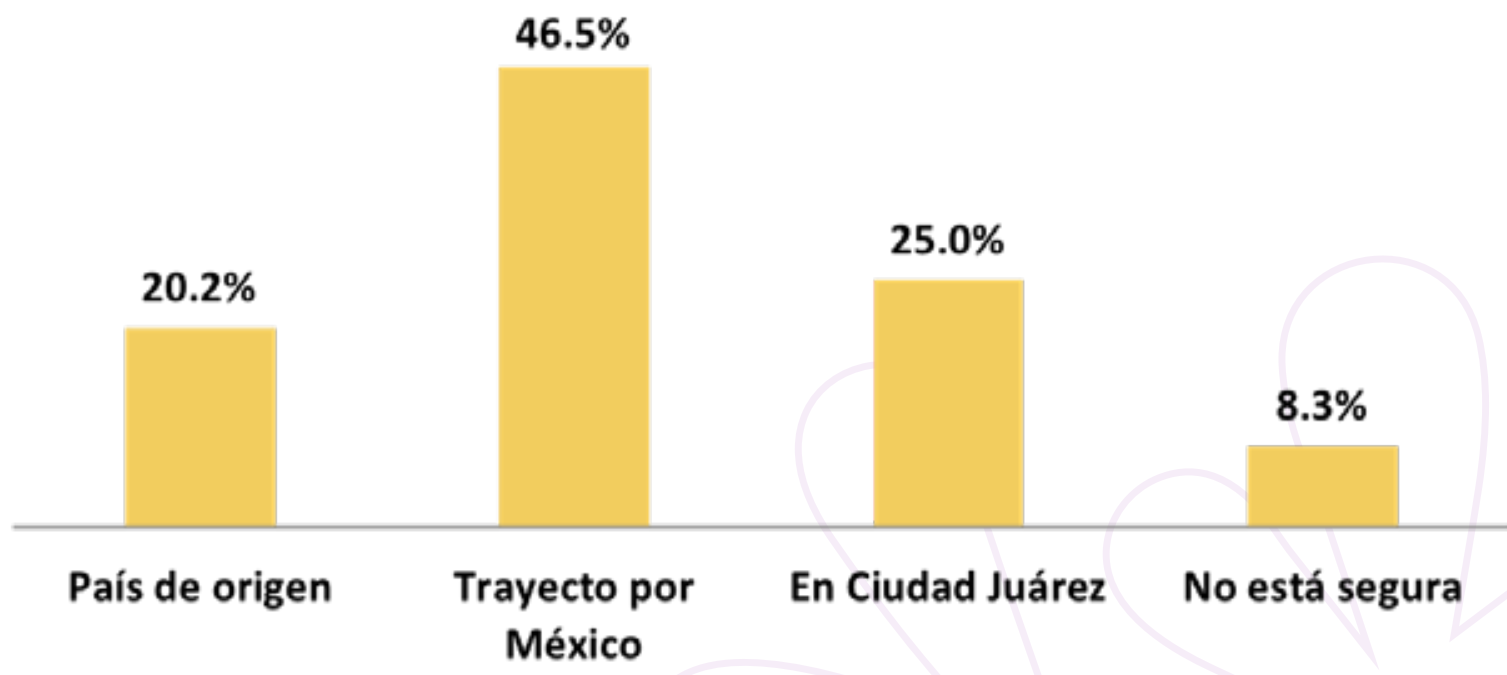

Con respecto a su estancia en Ciudad Juárez, se les cuestionó sobre su capacidad de atender sus necesidades de SSR como les gustaría poder hacerlo. Un 59.3\% señalo que no ha podido atenderse en Ciudad Juárez como le gustaría (ver gráfica 7). 
NECESIDADES Y ATENCIÓN EN SALUD SEXUAL Y

REPRODUCTIVA DE MUJERES MIGRANTES EN MÉXICO

Volumen 1

Gráfica 7. Distribución porcentual de poder atender sus necesidades de salud sexual como le gustaría, 2021

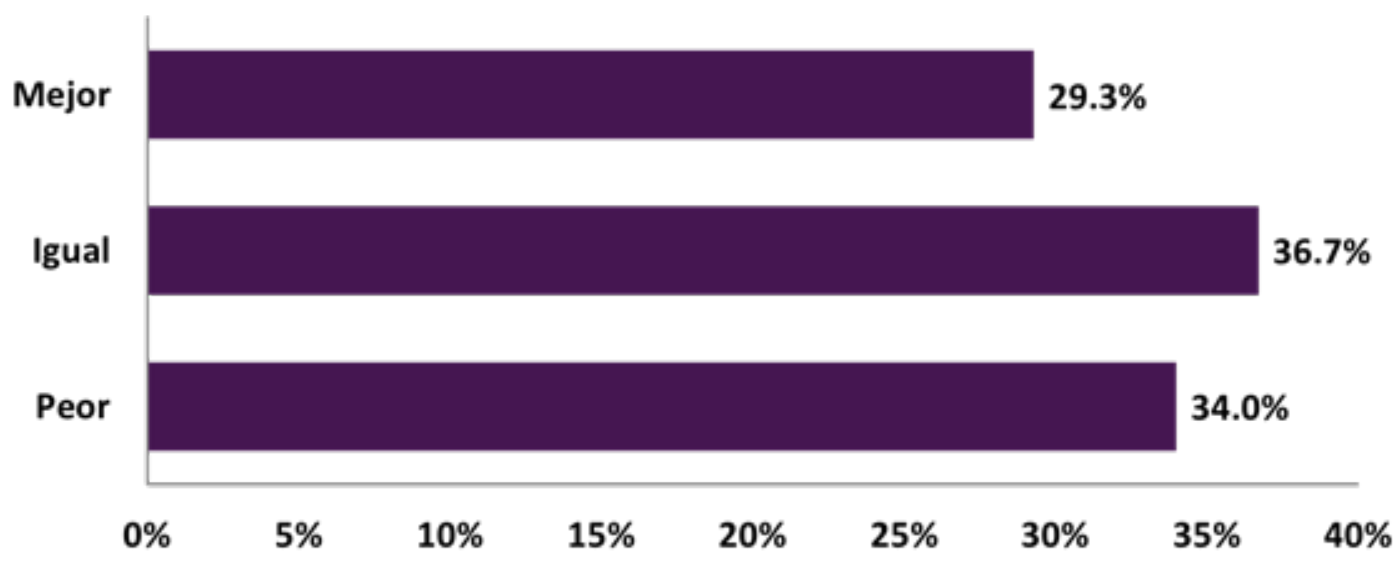

Para finalizar, se les pidió a las encuestadas que hicieran una comparación sobre la manera en que podían atender sus necesidades de SSR en Ciudad Juárez en relación con la manera en que lo hacían en su país de origen. La proporción de mujeres que consideran que es peor en Ciudad Juárez difiere solamente en 4.4 puntos porcentuales de las que lo consideran mejor que en su lugar de origen (ver gráfica 8).

Gráfica 8. Distribución porcentual de comparación de situación en temas de SSR en país de origen y en la actualidad, 2021

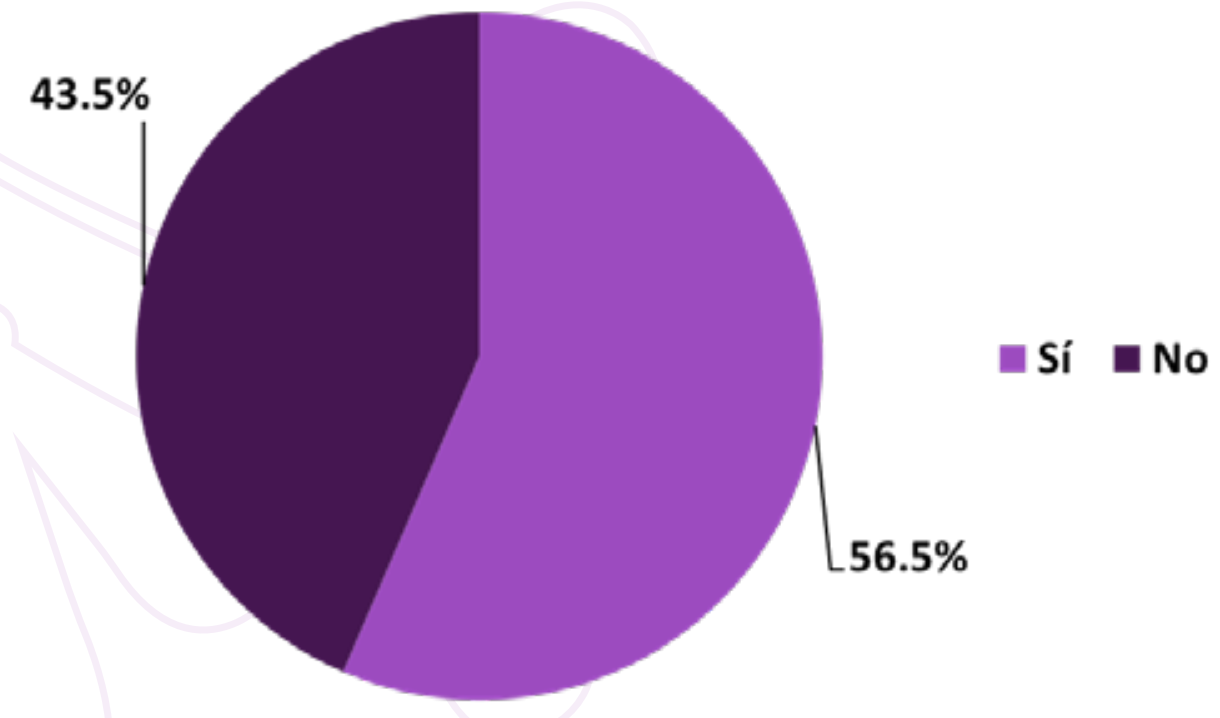

Fuente: Elaboración propia 


\section{NECESIDADES Y ATENCIÓN EN SALUD SEXUAL Y REPRODUCTIVA DE MUJERES MIGRANTES EN MÉXICO}

Volumen 1

\section{DISCUSIÓN}

El género y sus inequidades, la violencia, y su preocupación por brindar condiciones de vida más seguras para sus hijas e hijos, cruzan los contextos de las mujeres migrantes entrevistadas, y las fuerza a migrar en condiciones adversas.

La gran mayoría de las mujeres migrantes entrevistadas en albergues tienen una escolaridad básica (65.3\%), son madres (92.5\%), y viajan con hijas y/o hijos. Casi la misma proporción de estas mujeres tiene pareja o está soltera (47.8\% y $47.7 \%$ respectivamente). $70.1 \%$ de las encuestadas llevaban un mes o menos en Ciudad Juárez, y la mayoría se encontraba ahí como parte de los Protocolos de Protección a Migrantes (PMM). Las violencias que viven en sus lugares de origen (ya sean de género, perpetradas por el crimen organizado o por el Estado), son las principales causas de la migración en el total de las mujeres encuestadas. Sin embargo, sólo el 14\% ha solicitado refugio en México, y un 56.8\% en Estados Unidos. La preocupación por no tener dinero, ni suficiente de comer y de beber, así como tener que dormir a la intemperie fue experimentada por más de la mitad de las mujeres encuestadas.

El trayecto por México es el periodo más complejo para atender las necesidades de SSR de las mujeres que deciden migrar, desde sus países, hacia Estados Unidos.

Un tema de SSR que aqueja a las mujeres migrantes encuestadas en el tránsito es la salud menstrual. La principal necesidad es contar con medicamentos para el dolor y facilidades para mantener una higiene menstrual. La mayoría contó con suficientes toallas o tampones nuevos, aunque no siempre pudo cambiarse cuando lo necesitó. Es probable que también se deba fortalecer la información sobre el uso de productos para un periodo menstrual saludable, pues casi un $40 \%$ de las encuestadas no sabía sobre el periodo de uso recomendado de un tampón lo que, por ejemplo, puede ponerlas en riesgo de un síndrome de shock tóxico9.

Pocas mujeres están buscando embazarse durante su trayecto migratorio y en su estancia en Ciudad Juárez. Menos del cinco por ciento de la población encuestada estuvo embarazada durante su tránsito por México. Fueron pocas las mujeres encuestadas que veían algo bueno en estar embazadas en el proceso de migración, aunque de las cuatro mujeres migrantes embarazadas que fueron parte del estudio, solo una mencionó no haber buscado el embarazo. La percepción de vulnerabilidad de continuar con un embarazo coincide con el reporte

9 Aunque es poco frecuente, no se asocia únicamente al uso de tampones, y hay recomendaciones sobre el tipo de tampón a usarse, contar con esta información es relevante para reducir el riesgo de presentar este síndrome (Schlievert \& Davis, ${ }^{2020}$ ). 
de las mujeres embarazadas que mencionaron mayor vulnerabilidad en cuestión de inseguridad alimentaria y violencia física y simbólica en relación con las mujeres no embarazadas en el trayecto. La disparidad entre la percepción de violencias (alrededor de un 40\%) entre mujeres embarazadas y no embarazadas puede estar relacionada con una mayor autopercepción de inseguridad o fragilidad debido al embarazo que genera un estado de susceptibilidad a identificar actos de violencia que otras mujeres no embarazadas naturalizan como parte de su condición de migrante irregular. Como resultado, en las mujeres no embarazadas puede haber un subregistro de experiencias de violencia.

Para evitar un embarazo no deseado, el $40 \%(n=102)$ de las mujeres encuestadas se colocó un método anticonceptivo antes de iniciar el viaje (la mayoría hormonales inyectables), y un porcentaje similar lo sigue usando en la actualidad (en Ciudad Juárez) (37\%). Sin embargo, $60 \%(n=161)$ de las mujeres entrevistadas no se colocó o usaba un método anticonceptivo antes de iniciar el trayecto migratorio, y solo $4.7 \%$ se colocó o usó un método durante el trayecto. Un bajo porcentaje de ellas desconoce sobre los métodos y dónde obtenerlos, su pareja no está de acuerdo, o tiene motivos religiosos para no usar anticonceptivos modernos. Para el resto, el principal motivo es no haberlo pensado, o no tener pareja. La abstinencia sería considerada clave (y posible) para evitar un embarazo no deseado. Pudiera ser que algunas de ellas consideren que una violación se da en un contexto en que la mujer provoca a quien la violenta, y por ello, se imaginan fuera de riesgo.

En cuanto a violencias, la del tipo psicoemocional es altamente reportada por las mujeres migrantes encuestadas, aunque también reportan violencia física, robo, y tocamientos inapropiados (con porcentajes similares o mayores a los reportados por Leyva, et.al. 2019). Esto a pesar de que el tiempo de viaje fue para la mayoría de ellas (72.4\%) menor a un mes. Puesto que este periodo incluye la estancia temporal en México y/o Estados Unidos, cabe la pregunta de si estas vejaciones se viven en mayor medida en el trayecto sin o con guías, en las estancias dentro de instalaciones de las autoridades migratorias en ambos países, o, aunque la probabilidad es menor, en lugares de hospedaje. 
Destaca también que $75.4 \%$ de las mujeres migrantes encuestadas considera la violencia física como un criterio para definir un acto de violación sexual, mientras que el 55\% considera que una violación la comete una persona desconocida. Esto sustenta la sospecha de subestimación de la violencia sexual, incluida la violación, que viven las mujeres migrantes de estudios previos (César Infante et al., 2013; Leyva-Flores et al., 2019). Sugiere además que futuras investigaciones que busquen indagar sobre las experiencias de violencia sexual de esta población, incluida la violación, hagan definiciones conjuntas (sin revictimizar a las participantes), con el fin de buscar un piso común que permita obtener mejor información sobre el tema. Aún con ello, los estudios brindarán aproximaciones, dado el estigma en torno a la violencia sexual, así como los procesos psicoemocionales que se viven de forma íntima y personal, y que deben de respetarse.

Un 17\% de las mujeres encuestadas reportaron haber tenido relaciones sexuales durante el trayecto migratorio por México. No se preguntó si estas habían sido consentidas o no. De las mujeres que tuvieron relaciones sexuales (17\% de las 266 mujeres encuestadas), alrededor de un tercio -se infiere- tuvo relaciones sin protección, pues tuvieron preocupación de haber contraído una infección de transmisión sexual (31.8\%) o haber quedado embarazada (34.1\%). Se reporta sintomatología en el área genital después del acto, relacionada a infecciones de transmisión sexual o de vías urinarias: dolor, comezón, problemas para orinar, y flujo vaginal con mal olor. La mayoría de las mujeres que buscaron atención por problemas de salud posteriores a una relación sexual, lo hicieron una semana después del evento, es decir, tiempo después de la ventana de oportunidad (72hrs) para prevenir un embarazo no deseado (anticoncepción de emergencia) y de brindar profilaxis postexposición (PEP) para prevenir una infección por $\mathrm{VIH}$.

En torno al embarazo, también se destaca que, 3 de las 15 mujeres que se embarazaron en el trayecto reportaron no haberlo deseado. Dos de ellas tuvieron un aborto (no se especifica si inducido). Aun cuando se tiene la opción de interrumpir un embarazo cuando el mismo no es deseado, las mujeres encuestadas desconocen sobre métodos de interrupción segura del embarazo: $68.6 \%$ consideró falso o mencionó no saber que existen pastillas (medicamentos) que provocan un aborto y no dañan a la mujer. La OMS establece que el misoprostol (preferentemente en combinación con la mifepristona) es un medicamento seguro para la interrupción del embarazo siempre y cuando se use con la información adecuada y actualizada, en las semanas de gestación recomendadas (Narasimhan et al., 2020; OMS, 2012). El análisis de los datos de la encuesta nacional de salud y nutrición (National Health and Nutrition Examination Survey). Cabe la posibilidad de que la pregunta en el cuestionario no fuera lo suficientemente específica en cuanto a las condiciones de uso de las pastillas, pero existe desinformación entre los métodos recomendados por la medicina alópata para el aborto seguro, pues casi el $40 \%$ de las mujeres 
encuestadas no sabía si el té de canela o de cilantro eran seguros para la interrupción.

La búsqueda y acceso a la atención en SSR es limitado durante el trayecto, pero facilitado por albergues, sobre todo durante las estancias prolongadas. En general, se reporta que la atención en centros de salud públicos es de calidad (respetuosa y comunicativa).

Un 70\% de las mujeres encuestadas considera haber podido atender su SSR de igual o mejor manera que en su país de origen. La atención la buscaron principalmente en albergues y centros de salud u hospitales públicos. En el caso particular de las mujeres embarazadas, el lugar de atención más recurrido fue un centro de salud. No se reporta rechazo en la atención a servicios públicos, lo cual es destacable, pues menos del 2\% de la población entrevistada cuenta con el CURP, que es un documento indispensable para acceso al trabajo formal y que la ley favorece como documento para recibir atención médica según la Ley General de Salud (Art 77 bis 7 ) (DOF, 2019).

Se sugiere que el problema principal que enfrentan las mujeres migrantes en tránsito por México para atender su SSR es el acceso y no la calidad de la atención. Las mujeres que accedieron a servicios de salud pública reportan, en general, haber recibido explicaciones, espacio para hacer preguntas, ser tratadas con respeto, calidez, y documentación sobre el tratamiento, de no haber experimentado actos o expresiones racistas o xenófoba. Dos consideraciones para profundizar sobre el tema: por un lado, vale la pena indagar sobre los perfiles que reportan menos calidad en la atención y/o discriminación (ej. recibir comentarios negativos por su color de piel); y por otro, realizar estudios con una mayor muestra de mujeres que han tenido más frecuencia de contacto con los servicios de salud.

Aunque la utilización de servicios de SSR requiere de una integración del sistema de salud (Vázquez et al., 2009) y no es responsabilidad única de las personas o poblaciones, el estudio devela barreras individuales para la búsqueda de atención:

a) Falta de información sobre a dónde acudir.

b) Restricciones de movilidad que viven ya sea por su guía, falta de dinero para el transporte, y/o más recientemente, por las medidas de prevención de contagio de COVID-19.

c) La falta de recursos económicos para un seguimiento continuo y/o especializado. Esta es una preocupación que puede inhibir la búsqueda de atención en centros de salud públicos y/o privados con resultados negativos para la salud. 
Sin embargo, es posible que incluso si se encuentran en condiciones de buscar atención, no lo hagan o lo retrasen, por falta de certezas sobre su derecho a la salud y sobre SSR. Dos ejemplos: 47.4\% de las mujeres entrevistadas no tenían la certeza sobre si una mujer migrante "sin papeles" puede ser atendida en una unidad médica en México. También, aproximadamente 40\% del total de encuestadas, tiene desconocimiento sobre las medidas de prevención de una infección de VIH o un embarazo no deseado con el uso de la anticoncepción de emergencia, o sobre la posibilidad de obtener un aborto legal bajo la causal de violación en todo México. El contexto migratorio de movilidad y marginación, así como la falta de información sobre los procesos de atención en el sistema de salud mexicano (dónde, cómo, cuándo), es un elemento también documentado como barrera en la zona sur de México (Vázquez-Quesada et al., 2021).

Siendo los albergues los principales espacios que ubican las mujeres para buscar atención en diversos temas de SSR durante su tránsito por México, destaca la oportunidad que se tiene para fortalecer, a lo largo de la ruta, sus capacidades materiales, de personal, de conocimiento, y de procesos, para proveer apoyo (información, consejería, atención, referencia, y acompañamiento) en temas de SSR. Como se ha mencionado, los resultados de la encuesta sugieren la necesidad de brindar información oportuna, científica, y de calidad a las mujeres migrantes que están en el albergue, independientemente de si se acercan o no para resolver un problema del momento ${ }^{10}$. En los temas de SSR de esta población se debe considerar el cuidado de hijos e hijas. La mayoría viaja acompañada de hijos o hijas y no todas cuentan con una red apoyo de pareja, amistades o familiares que puedan brindar apoyo para su cuidado y manutención.

Para ello, además de ofrecer y facilitar capacitación en SSR al personal de los albergues, se requiere apoyarlos técnica y económicamente para fortalecer la atención y apoyo que brindan a las mujeres migrantes (preferentemente con protocolos que establezcan el quién, cómo, y cuándo). Actualmente, por ejemplo, en el caso de las mujeres embarazadas, y debido en parte a que son pocos los casos en relación con el total de la población de mujeres migrantes, la atención a esta subpoblación en los albergues se da caso por caso, y no existe un protocolo establecido para su atención. En el mapeo realizado por Population Council, sobre la atención en SSR que brindan las OSCs en siete estados de la república, incluidos los albergues, destaca también la intención, atención, y seguimiento que estas organizaciones brindan en diversos temas de SSR, aun sin protocolos de actuación que faciliten el manejo de casos (Larrea-Schiavon et al., 2021).

\footnotetext{
10 Información sobre salud menstrual (uso del tampón), VIH (profilaxis pre y post exposición), métodos de interrupción segura del embarazo y acceso a servicios de aborto legal en México, así como violencias de género (incluida la violencia sexual).
} 
Asimismo, destaca que, aunque el periodo más difícil para la atención en SSR de las mujeres migrantes fue el tránsito por México, ninguna de ellas anticipó una larga espera en la frontera norte de México. En este sentido, pocas de ellas llevaban suficiente tiempo en Ciudad Juárez como para reportar necesidades de SSR, y búsqueda de atención. La inesperada permanencia en Ciudad Juárez implicó que las mujeres encuestadas no pudieran planificar el periodo de espera de la misma forma en que planificaron algunos aspectos del trayecto. Un ejemplo es el cálculo de recursos económicos, hecho con base en lo que se anticipaba únicamente para el trayecto. Para las mujeres que buscan asilo en Estados Unidos, el tiempo de espera en México no depende de ellas; y mucho menos la resolución de su proceso migratorio. Este estado de incertidumbre complica la planeación de aspectos como el cuidado de hijos e hijas y la atención a la SSR. Con esto en mente, futuras investigaciones deben de enfocarse en las necesidades y atención en este ámbito de la salud de mujeres migrantes (aún en tránsito) en las ciudades de espera.

El presente estudio presenta limitaciones y se desarrolló en medio de la pandemia de COVID-19, lo que requirió una fructífera colaboración para la investigación con personal de los albergues, que construyeron capacidades técnicas. La pandemia del COVID-19 impuso ciertas restricciones a la recolección datos que resultaron en un alargamiento del tiempo de trabajo de campo por varios meses ya que, por momentos, el acceso a los albergues estuvo completamente negado. Otro factor que influyó en el tiempo de recolección fue el bajo flujo de mujeres migrantes extranjeras por Ciudad Juárez en relación a años recientes. El flujo de esta población extranjera comenzó a descender a principios de 2020 debido en parte al cierre de fronteras en diversos países de la ruta migratoria incluyendo México-Estados Unidos y la suspensión del proceso de asilo debido a la pandemia y los cambios en el gobierno federal en Estados Unidos producto de las elecciones del 2020.

Con respecto a medidas de protección contra el COVID-19, los datos indican que una tercera parte de la población entrevistada no se vacunaría si se lo ofrecieran. Esto sugiere la necesidad de entender mejor las razones de esta negativa y, con base en eso, generar una campaña de vacunación para promover la disposición de esta población a vacunarse. También se requiere que las vacunas se le ofrezcan. 


\section{CONCLUSIÓN}

Los datos recabados por medio de la encuesta a mujeres migrantes en situación migratoria irregular hospedadas en albergues de Ciudad Juárez muestran las dificultades que tiene esta población para identificar y atender una diversidad de necesidades de salud sexual y reproductiva (SSR), sobre todo en el trayecto por México. Se sugiere que una problemática central es el acceso a servicios, más que la calidad de los servicios prestados para aquellas que pueden buscarlos y utilizarlos. Esto pone en evidencia la necesidad de ampliar la información y consejería en estos temas, tanto en sus países de origen, como en los momentos de contacto que se tienen con ellas en México (albergues, centros de salud, instituciones gubernamentales como la COMAR) ${ }^{11}$. En este reporte se presenta una parte importante de los datos recabados. No obstante, mucha más información, así como maneras de analizarla quedan disponibles para futuras publicaciones. Un estudio a detalle de la experiencia de las mujeres embarazadas durante el trayecto debe de estar en esos esfuerzos.

La prevención, atención y disfrute de la SSR cruza por el conocimiento y comportamiento que las personas tengamos sobre este aspecto de la salud, aunque su base necesaria es un contexto favorable y habilitante para su disfrute. A pesar de sus limitaciones, el estudio muestra un panorama amplio de las necesidades de SSR de las mujeres migrantes en tránsito por México. Aunque no indaga sobre temas clave como estrategias de resiliencia de las mujeres y experiencias positivas en torno a la SSR ${ }^{12}$, se une a una agenda de investigación, todavía con mucho potencial de crecimiento, para entender mejor a esta población, sus necesidades, y cómo hacer para garantizar, entre todas y todos, su derecho a una salud integral en territorio mexicano (para empezar).

11 Esta sugerencia no resta ningún mérito al invaluable trabajo que muchas organizaciones de la sociedad civil (OSCs) y Organismos Internacionales realizan en Centroamérica y México para atender la SSR de las personas. La sugerencia es potenciar el logro de sus objetivos a través de su fortalecimiento de sus capacidades técnicas y económicas.

12 Esta reflexión la retomamos de la exposición de Nataly LLañez, "Necesidades en Salud Sexual y Reproductiva de mujeres y hombres migrantes centroamericanos en Tijuana". Agosto ${ }^{11}$ de ${ }^{2021}$. Disponible en https://www.youtube. com/watch?v=-aBDNnKfoCE 


\section{NECESIDADES Y ATENCIÓN EN SALUD SEXUAL Y REPRODUCTIVA DE MUJERES MIGRANTES EN MÉXICO}

Volumen 1

\section{REFERENCIAS}

Ataiants, J., Cohen, C., Riley, A. H., Tellez Lieberman, J., Reidy, M. C., \& Chilton, M. (2018). Unaccompanied Children at the United States Border, a Human Rights Crisis that can be Addressed with Policy Change. Journal of Immigrant and Minority Health, 20(4), 1000-1010. https://doi.org/10.1007/s10903-0170577-5

DOF. (2019). DECRETO por el que se reforman, adicionan y derogan diversas disposiciones de la Ley General de Salud y de la Ley de los Institutos Nacionales de Salud. 29/11/2019. http://www.dof. gob.mx/nota_detalle.php?codigo=5580430\&fecha=29/11/2019\#: :text=UNIDOS MEXICANOS\%2C

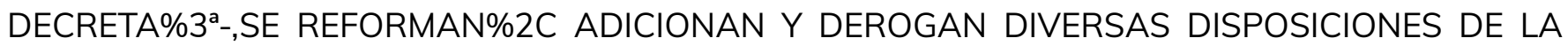
LEY,Artículo Primero.\&text=Artículo $2^{\circ}$.,-- ...\&text=El disfrute de servicios de,

Ellsberg, M., \& Heise, L. (2013). Researching Violence Against Women. Who, 78(June), 33-35. https://doi. org/10.4135/9781446269930

Gabriela Díaz Prieto y Gretchen Kuhner. (2014). Un viaje sin rastros. Mujeres migrantes que transitan por México en situación irregular (L. L. C. de D. Editores S.A. de C.V., IMUMI (ed.)).

Heredia Zubieta, C. (coord. ). (2016). El sistema migratorio mesoamericano. El Colegio de la Frontera/CIDE. Infante, Cesar, Leyva-Flores, R., Gutierrez, J. P., Quintino-Perez, F., Torres-Robles, C. A., \& Gomez-Zaldívar, M. (2020). Rape, transactional sex and related factors among migrants in transit through Mexico to the USA. Culture, Health \& Sexuality, 22(10), 1145-1160. https://doi.org/10.1080/13691058.2019.16 62088

Infante, César, Silván, R., Caballero, M., \& Campero, L. (2013). Sexualidad del migrante: Experiencias y derechos sexuales de centroamericanos en tránsito a los Estados Unidos. Salud Publica de Mexico, 55(SUPPL.1). https://doi.org/10.21149/spm.v55s1.5098

Larrea-Schiavon, S., Vázquez-Quesada, L., Basurto-Alcalde, E., Polgovsky, N., Vieitez, I., \& Pooja, S. (2021). Atención de la salud sexual y reproductiva de mujeres migrantes: Un mapeo de actores de la sociedad civil en México, 2020. In Population Council (p. 47). Population Council. https://doi.org/10.31899/ sbsr2021.1031

Leyva-Flores, R., Infante, C., Gutierrez, J. P., Quintino-Perez, F., Gómez-Saldivar, M. J., \& Torres-Robles, C. (2019). Migrants in transit through Mexico to the US: Experiences with violence and related factors, 2009-2015. PLoS ONE, 14(8), 2009-2015. https://doi.org/10.1371/journal.pone.0220775

Leyva Flores, R., Infante Xibillé, C., \& Quintino Pérez, F. (2016). Migrantes En Tránsito Por México: situación de salud, riesgos y acceso a servicios de salud. 


\section{NECESIDADES Y ATENCIÓN EN SALUD SEXUAL Y REPRODUCTIVA DE MUJERES MIGRANTES EN MÉXICO}

Volumen 1

Narasimhan, M., Logie, C. H., Gauntley, A., Gomez Ponce de Leon, R., Gholbzouri, K., Siegfried, N., Abela, H., \& Ouedraogo, L. (2020). Self-care interventions for sexual and reproductive health and rights for advancing universal health coverage. Sexual and Reproductive Health Matters, 28(2). https://doi.org/ $10.1080 / 26410397.2020 .1778610$

National Immigrant Justice Center. (2021). Conozca Sus Derechos: Los Protocolos de Protección a Migrantes y "Permanecer en México. FAQ. https://immigrantjustice.org/es/know-your-rights/conozca-susderechos-los-protocolos-de-proteccion-migrantes-y-permanecer-en-mexico\#: :text=MPP significa \%22Protocolos de Protección,asilo en los Estados Unidos.

OMS. (2012). Aborto sin riesgos. Organizacion Mundial de La Salud, 134. http://apps.who.int/iris/ bitstream/10665/77079/1/9789243548432_spa.pdf

OMS. (2018). Género y Salud. 2018. https://www.who.int/es/news-room/fact-sheets/detail/gender

Schlievert, P. M., \& Davis, C. C. (2020). Device-Associated Menstrual Toxic Shock Syndrome. Clinical Microbiology Reviews, 33(3). https://doi.org/10.1128/CMR.00032-19

UNICEF. (2021, October 11). 2021 records highest ever number of migrant children crossing the Darien jungle towards the U.S. https://www.unicef.org/press-releases/2021-records-highest-ever-numbermigrant-children-crossing-darien-jungle-towards-us

UPMRIP.(2021).BoletínEstadísticoMensual.https://portales.segob.gob.mx/work/models/PoliticaMigratoria/ CEM/Estadisticas/Boletines_Estadisticos/2021/Boletin_2021.pdf

Vázquez-Quesada, L. M., Larrea-Schiavon, S., Marín, T. T., Muñoz García, G. B., Basurto, E., Ochoa, B., Cortés-Maruris, B., Sosa, V., Martínez, E., Lombardini, N., Santoro, C., Guillermo, M., Berdichevsky, K., \& Vieitez, I. (2021). Mujeres migrantes en Tapachula: barreras y facilitadores para el acceso a la salud sexual y reproductiva en 2020. Centro Nacional de Equidad de Género y Salud Reproductiva, Ipas CAM, Médicos del Mundo, Population Council.

Vázquez, M. L., Vargas, I., Unger, J. P., Mogollón, A., Da Silva, M. R. F., \& De Paepe, P. (2009). Integrated health care networks in latin America: Toward a conceptual framework for analysis. Revista Panamericana de Salud Publica/Pan American Journal of Public Health, 26(4), 360-367. https://doi.org/10.1590/ S1020-49892009001000012 